\title{
Reduction of maximum tsunami run-up due to the interaction with beachfront development - application of single sinusoidal waves
}

\author{
N. Goseberg \\ Franzius-Institute for Hydraulic, Waterways and Coastal Engineering, Leibniz University Hanover, Nienburger Str. 4, \\ 30167 Hanover, Germany
}

Correspondence to: N. Goseberg (goseberg@fi.uni-hannover.de)

Received: 23 February 2013 - Published in Nat. Hazards Earth Syst. Sci. Discuss.: 11 April 2013

Revised: 7 October 2013 - Accepted: 24 October 2013 - Published: 22 November 2013

\begin{abstract}
Experiments are presented that focus on the interaction of single sinusoidal long waves with beachfront development on the shore. A pump-driven methodology is applied to generate the tested waves in the wave flume. The approaching waves firstly propagate over a horizontal bottom, then climbing up a 1 in 40 beach slope. The experiments reported here are confined to the surf similarity parameter of the waves ranging from $\xi=7.69-10.49$. The maximum runup of the tested waves under undisturbed conditions agrees well with analytical results of Madsen and Schäffer (2010). Beachfront development is modelled with cubic concrete blocks (macro-roughness (MR) elements). The obstruction ratio, the number of element rows parallel to the shoreline as well as the way of arranging the MR elements influences the overall reduction of maximum run-up compared to the undisturbed run-up conditions. Staggered and aligned as well as rotated and non-rotated arrangements are tested. As a result, nomograms are finally compiled to depict the maximum runup reduction over the surf similarity parameter. In addition, some guidance on practical application of the results to an example location is given.
\end{abstract}

\section{Introduction}

Facing sea level rise the implications of coastal hazards such as cyclones, storm surges, floods or tsunami to endangered stretches of coastlines will increase in the future. By combining geophysical and socio-economic data sets, Nicholls and Small (2002) found that the population density of the near-shore coastal zone is three times higher than the average global population density. More interestingly, the highest number of inhabitants around $4 \times 10^{8}$ to $6 \times 10^{8}$ was found within the first $10 \mathrm{~km}$ inland of the shoreline based on census data of 1990 (Small et al., 2000; Nicholls and Small, 2002). Accelerated urbanization and increasing construction activity is usually fostered in close proximity to the shoreline when population is substantially growing. Concurrently, many of these coastlines worldwide are situated in close proximity to subduction zones from where earthquake induced tsunami originate which is dramatically underlined by recent life-taking events such as the Indian Ocean tsunami in 2004 or the 2011 Tohoku-Oki tsunami in Japan. In this regard the question arises how beachfront development in urbanized areas affect the run-up of tsunami. Some researchers recently made advancements in deducing water levels and flow velocities from eye-witness reports and video observations during the run-up and draw-down phases of tsunami indicating that flow velocities are in the range of $2 \mathrm{~m} \mathrm{~s}^{-1}$ to $11 \mathrm{~m} \mathrm{~s}^{-1}$ (Fritz et al., 2006, 2012; Shimozono et al., 2012). These water level and velocity measurements are most important for building design purposes since it is inevitable to validate analytical and numerical models which are capable of computing maximum fluid forces in the tsunami run-up zone (Yeh, 2006). Besides the purpose of establishing and enhancing current design guidelines aimed at constructing tsunami-proof infrastructure in a tsunami run-up zone, it is equally important to understand how maximum wave run-up is affected since evacuation and hazard mitigation planning often relies on information about the spatio-temporal extent of the tsunamiinduced inundation. In the tsunami run-up zone the flow is often observed to consist of an air, water and sediment phase which increases the difficulty to find analytical or simplified numerical solutions to the problem. Hence, in literature 
a wide variety of laboratory studies documents the effort to understand how bores interact with surface-piercing vertical structures (Ramsden and Raichlen, 1990; Ramsden, 1996), the sediment transport initiated by solitary or cnoidal waves (Moronkeji, 2007), the forces on a single square column modelling free standing infrastructure located close to the shoreline (Nistor et al., 2009), the process of dam-break flow through an idealised city (Soares-Frazão and Zech, 2008) or the interaction between solitary-type wave (Cox et al., 2009) or error-function wave (Rueben et al., 2011) and the town of Seaside, Oregon, US. Then, Goseberg and Schlurmann (2011) investigates interaction of coastal development in an idealized form by means of numerical two-dimensional shallow-water wave modelling in comparison with preliminary experimental data. Another study details the general dependence of building density to the overall run-up of long waves on a given shore (Goseberg and Schlurmann, 2012). Although some improvements were reported on the numerical modelling of wave-structure interaction (i.e. Tomita et al., 2007), nowadays it still remains cumbersome to cover the entire domain of a tsunami approaching the shoreline while interacting with beachfront development in three dimensions numerically. Hence in this study scale experiments were chosen methodically where the approaching tsunami was modelled by means of single sinusoidal waves in a water depth of $30 \mathrm{~m}$ (prototype condition). Although beachfront development and urban pattern are usually randomly distributed in prototype, it is decided to approximate those building pattern by regular structures, since from literature no hints on the parametrization of building density have been determined. In total, four different patterns of MR elements modelling beachfront development were combined: (a) aligned, nonrotated, (b) aligned, rotated, (c) staggered, non-rotated and (d) staggered, rotated. The region of interest in this study is restricted to the shallow water region from where the wave starts climbing up a plane beach and the tsunami run-up zone where the long-wave interacts with beachfront development. Even though it is unclear under which conditions building collapse is stimulated in prototype conditions, it is herein assumed that MR elements remain stable all the time. Currently, the flow processes incorporating non-stationary conditions during wave run-up with blocking MR elements on the shore have received the least attention from hydraulic engineering perspective and hence remain an active area of research. Hence, in the framework of the above model concept the following research questions should be addressed:

- How is the run-up of long waves caused by submarine earthquakes basically modified under the influence of beachfront development?

- How large is the reduction of maximum wave run-up compared to an undisturbed case and which processes or parameters dominate this reduction?
Table 1. List of sinusoidal waves used, values refer to measurements at the wavemaker, water depth $h=$ is $0.31 \mathrm{~m}$, period $T$ is $60 \mathrm{~s}$, linear wave length $L_{0}$ becomes $104.63 \mathrm{~m}, \xi_{0}$ surf similarity, no. of repetitions is given under "Rep".

\begin{tabular}{lllllll}
\hline $\begin{array}{l}\text { No. } \\
\text { ID }\end{array}$ & $\begin{array}{l}a_{\mathrm{cr}} \\
{[-]}\end{array}$ & $\begin{array}{l}H_{0} \\
{[\mathrm{~m}]}\end{array}$ & $\begin{array}{l}a_{\mathrm{cr}} / h_{0} \\
{[\mathrm{~s}]}\end{array}$ & $\begin{array}{l}H_{0} / L_{0} \\
{[\mathrm{~m}]}\end{array}$ & $\begin{array}{l}\xi_{0} \\
{[-]}\end{array}$ & $\begin{array}{l}\text { Rep. } \\
{[-]}\end{array}$ \\
\hline 1 & 0.016 & 0.031 & 0.052 & $2.963 \times 10^{-4}$ & 10.49 & 2 \\
2 & 0.018 & 0.036 & 0.058 & $3.441 \times 10^{-4}$ & 9.79 & 39 \\
3 & 0.020 & 0.041 & 0.064 & $3.918 \times 10^{-4}$ & 9.10 & 2 \\
4 & 0.023 & 0.046 & 0.074 & $4.396 \times 10^{-4}$ & 8.57 & 2 \\
5 & 0.026 & 0.052 & 0.083 & $4.970 \times 10^{-4}$ & 8.06 & 2 \\
6 & 0.030 & 0.059 & 0.097 & $5.639 \times 10^{-4}$ & 7.69 & 31 \\
\hline
\end{tabular}

The problem of long waves which are climbing up a plane, sloping beach after propagating over a horizontal bottom is depicted in Fig. 1. Firstly, before the wave front reaches the shoreline, shoaling and refraction constitutes the main wave modification. At a specific water depth or for specific nonlinearity wave breaking may occur. Yet, Madsen and Fuhrman (2008) pointed out that wave breaking is mostly dedicated to shorter waves riding on top of lower frequent tsunami waves. Then, during their run-up and subsequent draw-down, the approaching tsunami may interact with beachfront development represented in this study by MR elements positioned at different distances to each other and in different arrangements on the beach above the still water line. In order to repeat this model situation, it is assumed that the first row of MR elements is always at the same distance to the still water line. One possible element combination as well as a longitudinal cross section are sketched schematically in Fig. 1, to demonstrate the model assumptions. Though the waves under consideration are indeed longer than the slope applied for the experiments, the setting is illustrated in Fig. 1 with spatially shorter waves for the sake of clarity. For details of the applied waves the reader is referred to Table 1.

Additionally, two top-view movies depicting a sample laboratory experiment are provided as supplementary material that illustrate how a long wave principally reaches beachfront development modelled by a staggered, rotated MR element configuration and then progresses through the urban agglomeration. Both wave run-up and subsequent draw-back are captured.

\section{Theoretical framework}

This research is accomplished by means of hydraulic modelling in laboratory. Downscaled idealised prototype conditions are utilised to analyse the effects of urban beachfront development to an approaching tsunami. Before experimental set-up and results are presented analytical formulae to the plain undisturbed run-up from literature are given. Facilitating dimensional analysis as presented in the Annex allows for 


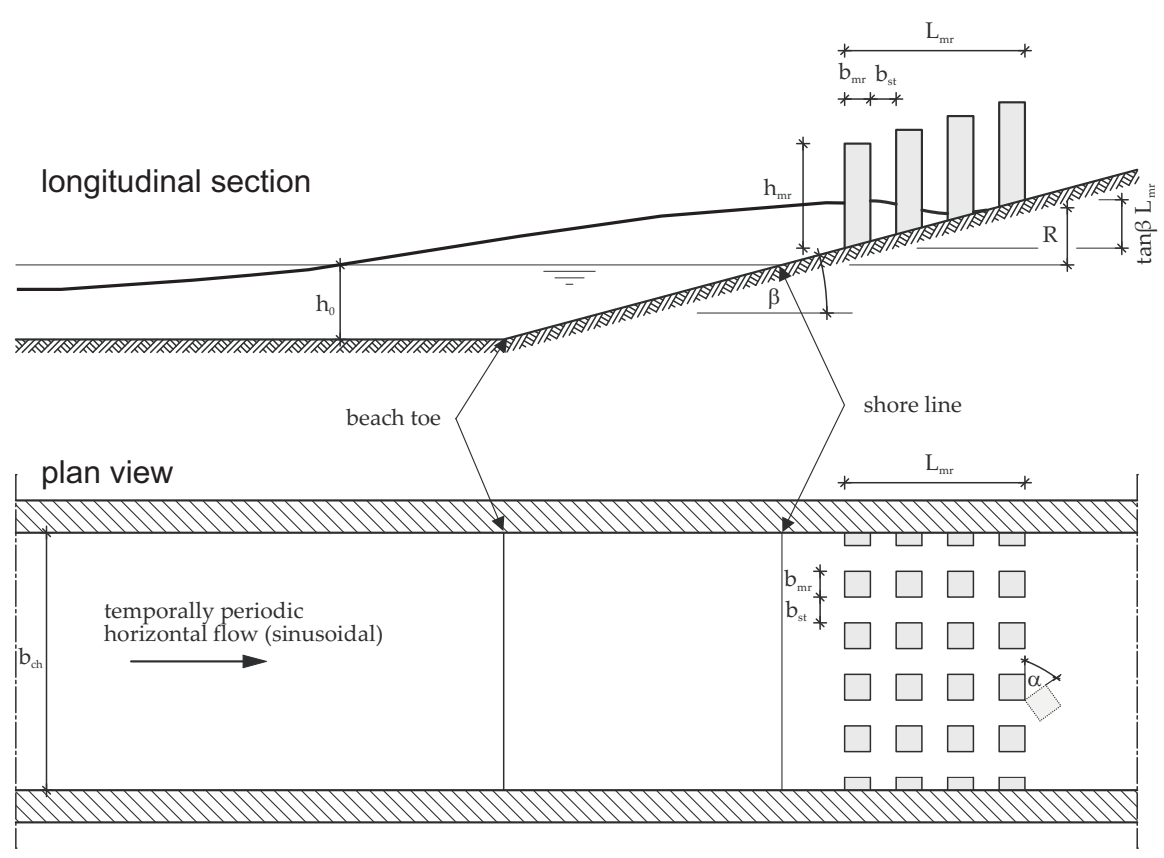

Fig. 1. Schematic sketch of the problem set-up and the definition of the used variables, $h_{0}$ water depth, $\alpha$ angle of rotation of MR, $\beta$ slope angle, $R$ wave run-up, $b_{\mathrm{mr}}$ and $h_{\mathrm{mr}}$ width and height of the macro-roughness elements, $b_{\mathrm{st}}$ distance between the macro-roughness elements. Spatial extent of the shown wave is not to scale. Experimentally investigated wave length significantly exceeds beach length (cf. Table 1).

the determination of key parameters that influence the process. Hence it is possible to limit experimental efforts to the most relevant parameters. In this study a variation of the surf similarity parameter in the aforementioned range is chosen.

\subsection{Analytical wave run-up}

Wave run-up was extensively studied in literature. Most commonly, the work of Hunt (1959) is referenced who reprocessed former published experimental studies, conducted additional experiments and analysed these aiming at design of sea walls and breakwaters. For breaking waves, the nondimensional run-up becomes a function of beach slope, incident wave height and wave steepness which reads

$\frac{R}{H_{0}}=\xi_{0}=\tan \beta\left(\frac{H_{0}}{L_{0}}\right)^{(-1 / 2)}$ for $0.1<\xi_{0}<2.3$

where $R / H_{0}$ denotes the relative run-up normalized by the deep water wave height $H, \xi_{0}$ is the surf similarity parameter. The angle $\beta$ denotes the beach slope. The non-breaking upper limit of wave run-up on a uniform slope is then given according to CEM US Army Corps (2002) reading

$$
\frac{R}{H_{0}}=\sqrt{2 \pi}\left(\frac{\pi}{2 \beta}\right)^{1 / 4}
$$

Equations (1) and (2) were derived on the basis of experimental research and thus the validity is limited to steep beach slopes between $1 / 10$ to vertical walls. Hence, additional formula have to be applied in the present cases where much milder slopes were investigated.

In the sequel, also solitary waves (Synolakis, 1987) or $N$ waves (Tadepalli and Synolakis, 1994) were addressed in connection with long-wave run-up. Often, the run-up formulas reported in literature were derived empirically and for the special conditions used in this research with long-wave periods and very mild beach slopes it is questionable if these approaches are valid to compare our experimental results with. However, recently Madsen and Schäffer (2010) proposed analytical solutions for the run-up and run-down based on the non-linear shallow water wave theory for various wave forms, where the duration and the wave height could be specified separately in order to overcome the length scale deficiency of available long-wave models. This analytical approach resulted in establishing run-up/run-down and velocity formula for various waveforms such as isoceles $N$ waves, single waves and sinusoidal waves but with the important exception that these waveforms did no longer exhibit a tie to wave height-to-depth ratio. The normalized run-up is summarized as a function of the surf similarity parameter derived, which reads (Madsen and Schäffer, 2010)

$\frac{R}{a_{0}}=\chi_{\operatorname{elev}} \pi^{1 / 4}\left(\frac{a_{0}}{h_{0}}\right)^{-1 / 4} \xi_{0}^{-1 / 2}$,

where $R$ denotes run-up, $a_{0}$ is offshore amplitude, $\chi_{\text {elev }}$ and $\chi_{\text {velo }}$ are shoreline elevation and velocity, $\Omega=2 \pi / T$ is a duration in analogy to the common wave period and 
$h_{0}$ is offshore water depth. Surf similarity $(\xi)$ is given by Eq. (4), which is based on the previously defined surf similarity Eq. (B5) but is recast by Madsen and Schäffer (2010) in terms of the effective duration $\Omega$ of the wave. It reads

$\xi=\sqrt{\pi}\left(\frac{a_{0}}{h_{0}}\right)^{-1 / 2}\left(\frac{\Omega^{2} h_{0}}{g \tan \beta^{2}}\right)^{-1 / 2}$,

where $\tan \beta$ describes the beach slope. A theoretical breaking criterion is equally given by Eq. (5) (Madsen and Schäffer, 2010)

$\frac{R_{\text {break }}}{a_{0}}=\frac{1}{\pi} \xi^{2}$.

For the experiments presented in this study, the analytical run-up formula derived by Madsen and Schäffer (2010) is applied for the purpose of result comparison.

\subsection{Definition of beachfront obstruction}

In order to apply a measure for the beachfront obstruction a number of variables are introduced to express the influence of MR elements on the wave run-up. Geometrical definitions are sketched in Fig. 1. Most importantly, one has to define cross $\left(\psi_{\mathrm{cs}}\right)$ and long-shore rates of obstruction $\left(\psi_{\mathrm{ls}}\right)$. Besides these horizontal obstruction rates, a component expressing the vertical obstruction of the flow cross section $\left(\psi_{\mathrm{mr}}\right)$ could be named similarly. Yet, vertical obstruction is only relevant when overtopping of MR elements is concerned which shall be excluded for the moment. The cross-shore obstruction ratio can be defined as

$\psi_{\mathrm{cs}}=\frac{L_{\mathrm{mr}}}{n \hat{b}_{\mathrm{mr}}}=\frac{n\left(\hat{b}_{\mathrm{mr}}+b_{\mathrm{st}}\right)-b_{\mathrm{st}}}{n \hat{b}_{\mathrm{mr}}}=\frac{n\left(b_{\mathrm{mr}} / \cos \varphi+b_{\mathrm{st}}\right)-b_{\mathrm{st}}}{n b_{\mathrm{mr}} / \cos \varphi}$

where $\hat{b}_{\mathrm{mr}}=b_{\mathrm{mr}} / \cos \varphi$ denotes the width of the MR elements according to their angle of rotation to the incident wave direction (cf. Fig. 4). The length of the obstructed beach in the direction of wave run-up is named $L_{\mathrm{mr}}$, which can be defined as follows

$L_{\mathrm{mr}}=n\left(b_{\mathrm{mr}}+b_{\mathrm{st}}\right)-b_{\mathrm{st}}$,

with $n$ denoting the number of MR element rows parallel to the still water line, $b_{\mathrm{mr}}$ defines the edge length of a single MR element and $b_{\text {st }}$ defines the distance from one MR element to the next (i.e. street width). The cross-shore rate of obstruction depends on the ratio of the number of element rows times the width to the length of the macro-roughness area in on-shore direction. This geometrical ratio accounts for the obstruction exposed to the in-land propagating flow. The ratio $\psi_{\mathrm{cs}}$ decreases if the street width tends to zero, $b_{\mathrm{st}} \rightarrow 0$. The ratio grows if the number of MR rows is increased. The long-shore obstruction ratio is given by

$\psi_{\mathrm{ls}}=\frac{\hat{b}_{\mathrm{mr}}}{\hat{b}_{\mathrm{mr}}+b_{\mathrm{st}}}=\frac{b_{\mathrm{mr}} / \cos \varphi}{b_{\mathrm{mr}} / \cos \varphi+b_{\mathrm{st}}}$, where $\hat{b}_{\mathrm{mr}}$ equally expresses the effective width of the MR elements with respect to the approaching wave front. The longshore rate of obstruction increases according to Eq. (8) when the ratio of the macro-roughness width to the sum of the street width plus the macro-roughness element width tends to unity. A long-shore rate of obstruction of unity is equivalent to a complete obstruction of the beach and results in full reflection of the wave and the run-up tongue. The above definitions are used to evaluate the change in long-wave run-up with respect to the incoming waves.

\section{Experimental set-up}

Building on the theoretical framework described above, the experimental set-up and the related experimental programme is outlined in the following. Results of dimensional analysis are utilized to decide which variables have to be varied. Details of the varied variables are reported in Sect. 3.2. Froude similitude is chosen to downscale prototype conditions since from dimensional analysis (cf. Appendix B) it can be ruled out that viscosity and surface tension may - under the constraint of too tiny length or timescales - falsify runup measurements significantly. The wave flume, its components to generate long waves as they are possibly generated by tsunamigenic sub-sea earthquakes as well as wave generation methodology have recently been described by Goseberg $(2011,2012)$ and Goseberg et al. (2013); readers are referred to those publications for detailed information whereas a brief outline is presented in Sect. 3.1.

\subsection{Wave flume}

The experiments were carried out in the closed-circuit wave flume (race-track type) at the Franzius-Institute for Hydraulic, Waterways and Coastal Engineering. A schematic drawing of the $56.94 \mathrm{~m}$ long flume illustrates the principal design of the facility (Fig. 2). The clear width of the flume amounts to $1.00 \mathrm{~m}$. The flume is made of two parallel and $19.00 \mathrm{~m}$ long straights whose ends are connected by two semicircles of $6.87 \mathrm{~m}$ diameter. While one of the straights accommodates the run-up region, the other integrates a pump station that allows for the acceleration and deceleration of the water body. The water depth is kept constant at $0.31 \mathrm{~m}$ during all the reported experiments.

For the purpose of generating long waves in the flume, it was separated into a reservoir and a propagation section by a 1 in 40 sloping beach wedge made of wood, sand, plaster and PVC board. Figure 2 also gives the location of the sloping beach section which is located opposite to the pump station. A solid impermeable wall completes the beach wedge at its upper limit to ensure that no water flows from the propagation to the reservoir section or vice versa. The beach is fully covered with poly-vinyl-chloride board and all remaining gaps are sealed with silicone to build a smooth surface for the run-up and drawdown process. 


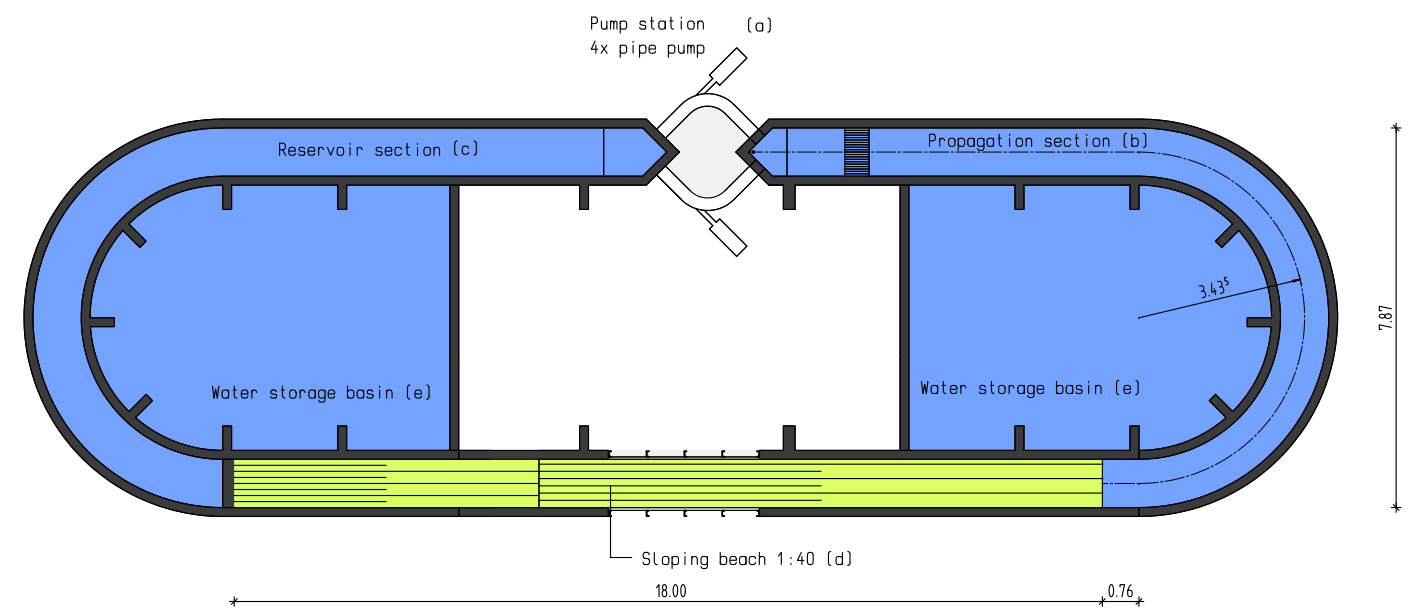

Fig. 2. Schematic drawing of the closed-circuit flume and its equipments, (a) pump station, (b) propagation section, (c) reservoir section, (d) sloping beach, (e) water storage basin (units in metre).

\subsection{Test programme}

In this study single sinusoidal waves with a fixed period $T=60 \mathrm{~s}$ were used to study the onshore interaction of long waves and beachfront development. In literature, many studies exist that apply solitary waves when tsunami evolution in the vicinity of the shoreline is investigated (e.g. Synolakis, 1987). Few studies yet are based on cnoidal waves (Moronkeji, 2007) while a variety of publications apply dambreak induced bores to study forces on free-standing structures on the beach (Ramsden, 1996). Following the argumentation of Madsen et al. (2008) it recently became questionable if solitons are well suitable to serve as a model for nearshore tsunami. A main argument from the authors was that solitons lack in terms of geophysical time- and length-scales that are typical of tsunami. This argument was recently underlined by offshore GPS and bottom pressure measurements at the Japanese coast originating from the 2010 Chilean earthquake detecting wave periods much longer than those replicable from the solitary wave assumption (Kawai et al., 2012). Additionally, with respect to the overarching goal to study the influence of beachfront development to the longwave run-up, the total duration of the interaction becomes important, which is comparatively short for commonly used solitary waves or Gaussian humps. Hence, it was deliberately chosen to step back to the most simple wave form possible in the laboratory. With respect to the length and timescales chosen, a period of $T=60 \mathrm{~s}$ was applied in this study leading to prototype condition periods of $T=600 \mathrm{~s}$ which is well in the range of measured realistic tsunami periods. Furthermore due to time constraints only leading depression waves were tested so far. Figure 3 presents the investigated waves with amplitude variations. Those applied single period sinusoidal waves consist of a leading wave trough followed by a wave crest. Prior and after these single sinusoidal wave periods surface elevation is kept constant at zero. Standard deviation is

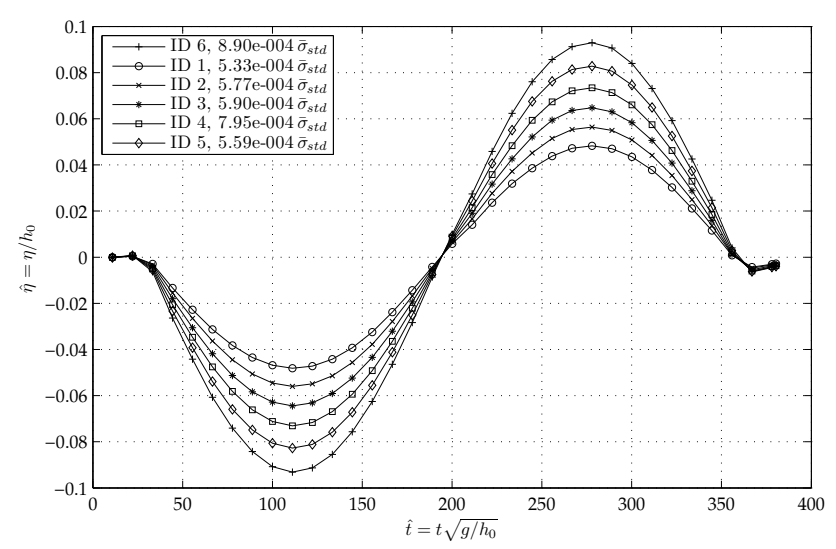

Fig. 3. Averaged non-dimensional surface elevation history for the six utilized waves, the markers denote the different waves heights, $\bar{\sigma}_{\text {std }}$ is the averaged standard deviation calculated from the entire number of experiments in each group.

additionally given in order to show quality of the generated waves and their repeatability. Due to a lack of instrumentation, no particle velocities under the wave trough and crest were measured continuously, though this depicts an interesting future research objective for the applied innovative wave generation method. Particle velocities were only measured a few times with a mobile current metre. Those resulting horizontal particle velocities yielded values in the range of the regime of the linear shallow-water wave theory; yet, further research is needed and will be published at a latter stage.

Table 1 lists the wave properties measured at the wavemaker and the repetitions. Some experiments were repeated quite often in order to investigate the repeatability of the wave generation method; results are reported in Goseberg (2012), who generally found satisfactorily small standard deviation for repeated experiments. 

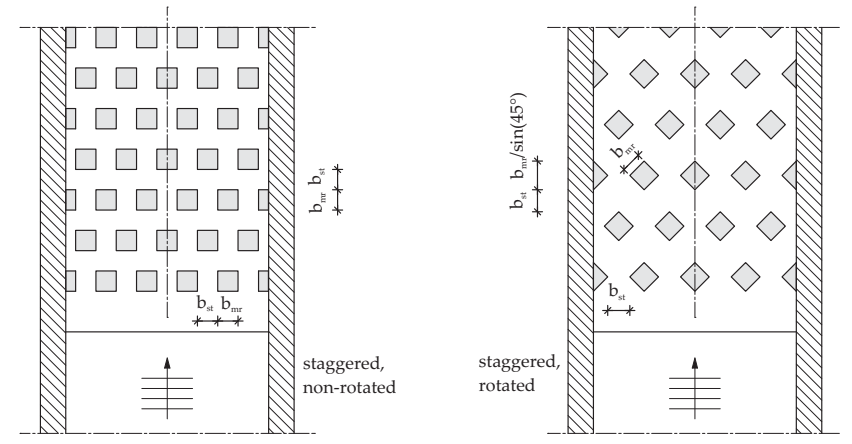

Fig. 4. Symmetry requirements for the configuration of the MR elements for a staggered, non-rotated configuration (left) and a staggered rotated configuration (right), drawing not to scale, demonstration of the axis of symmetry at the flume wall, which always cuts an MR element in the half.

The MR elements were manufactured as solid, cubic blocks with an edge length of $0.10 \mathrm{~m}$ manufactured with a standard concrete mixture. As form work a standard cube mold was utilized to pour in the concrete. A total number of 100 complete cubes and 20 half cubes were manufactured. Figure 5 depicts an example configuration of the MR elements in the flume. One notices some minor imperfections stemming from the production process of the MR elements (blowholes, dents) but in summary the quality of the concrete cubes and their surfaces is regarded to be satisfactory for the experiments. Table 2 further outlines the number of experiments and the applied wave conditions during the experiments. With respect to the MR configurations different total numbers of experimental runs were possible.

The varied variables leading to the total number of experimental runs are the distance between the elements $\left(b_{\mathrm{st}}\right)$, the number of MR element rows $(n)$, the angle of the elements with respect to the incident wave direction $(\varphi)$ and the choice of an offset between the element rows. In case of the aligned configuration ("al" in Table 2), four street widths were realized in the flume which are $2.5 \mathrm{~cm}, 4.2 \mathrm{~cm}, 6.6 \mathrm{~cm}$ and $10.0 \mathrm{~cm}$, whereas for the staggered configuration ("st" in Table 2) only three street widths were used $(2.5 \mathrm{~cm}, 5.9 \mathrm{~cm}$, $10.9 \mathrm{~cm}$ ). This is because the flume width is limited to $1.0 \mathrm{~m}$. Two element angles $\varphi \in\left(0^{\circ}, 45^{\circ}\right)$ are further conceivable. Additionally, three different numbers of macro-roughness element rows were tested in order to investigate the influence of the obstructed long-shore length, $n \in(1,5,10)$. A prerequisite for the experiments was the strict compliance of twodimensionality and thus symmetry. In preliminary experiments it was found that the application of whole-numbered distances between the MR elements led to large deviations of the maximum measured run-up compared to cases where symmetry conditions directly at the flume walls were meet. Figure 4 depicts two examples of MR configuration in the flume were correct application of symmetry was given.
Table 2. Number of conducted experiments classified according to the utilized wave properties listed in Table 1 and to the MR combinations $\Gamma$, "al" aligned, "st", staggered.

\begin{tabular}{lllllll}
\hline ID & w/o MR & $\begin{array}{l}\text { al } \\
\varphi=0^{\circ} \\
\Gamma=1\end{array}$ & $\begin{array}{l}\text { al } \\
\varphi=45^{\circ} \\
\Gamma=2\end{array}$ & $\begin{array}{l}\text { st } \\
\varphi=0^{\circ} \\
\Gamma=3\end{array}$ & $\begin{array}{l}\text { st } \\
\varphi=45^{\circ}\end{array}$ & $\begin{array}{l}\Sigma=4 \\
\Gamma\end{array}$ \\
\hline 1 & 2 & 12 & 9 & 8 & 6 & 37 \\
2 & 39 & 12 & 9 & 8 & 6 & 74 \\
3 & 2 & 12 & 9 & 8 & 6 & 37 \\
4 & 2 & 12 & 9 & 8 & 6 & 37 \\
5 & 2 & 12 & 9 & 8 & 6 & 37 \\
6 & 31 & 13 & 10 & 8 & 6 & 68 \\
$\Sigma$ & 78 & 73 & 55 & 48 & 36 & 290 \\
\hline
\end{tabular}

In both cases it was required to correctly close any distances left between the half MR elements and the flume walls in order to circumvent any flow through these gaps. Additional photographs of these wall and symmetry treatments are shown in Fig. 5.

\subsection{Measurements and instrumentation}

In order to evaluate run-up reduction due to the interaction of the incoming waves with the beachfront development, a large set of parameters was recorded. Besides the measurement of surface elevations along the horizontal bottom, water depths were collected on the beach slope. The maximum run-up was captured with a drift-line approach. Additionally, flow velocities were recoded at selected positions along the propagation path. A comprehensive sketch of positions of sensors is given in Fig. 6.

According to the local water depth wave heights were measured by resistance wave gauges (RWG). Those positions in the vicinity of or on the sloping beach are indicated in Fig. 6. Furthermore, a few times selected experiments were conducted where the positions of the RWG's were shifted to the bent section of the wave flume in order to investigate how the bend might affect the wave propagation. Details are given in Goseberg (2013). The non-linearity of the RWG (Delft Hydraulics Laboratory, range $0.5 \mathrm{~m}$ ) is specifically $0.5 \%$ of the measurement range. Where still water depth did not exceed $0.2 \mathrm{~m}$, upward facing pressure sensors (PRS) were mounted inside the beach slope (orthogonal to the surface) in order to capture water level variations during the experiments. Two different sorts of sensors were in operation - TM/N sensors by STS AG (range 0.0 to $1.5 \mathrm{~m}$, nonlinearity $\pm 0.25 \%$ FS) and PDCR 1830 by GE Druck (range 0.0 to $0.7 \mathrm{~m}$, non-linearity $\pm 0.1 \% \mathrm{FS}$ ). All sensors were calibrated against a calibration unit before mounting. Similarly, exact positions of the PRS are indicated in Fig. 6. Ultrasonic distance sensors (UDS) were utilized to detect water level variations in the landward facing beach area behind the MR elements (Wehrhahn manufacturer, range 0.07 to $2.00 \mathrm{~m}$ ). Sound transducers of the UDS are mounted $0.40 \mathrm{~m}$ above 

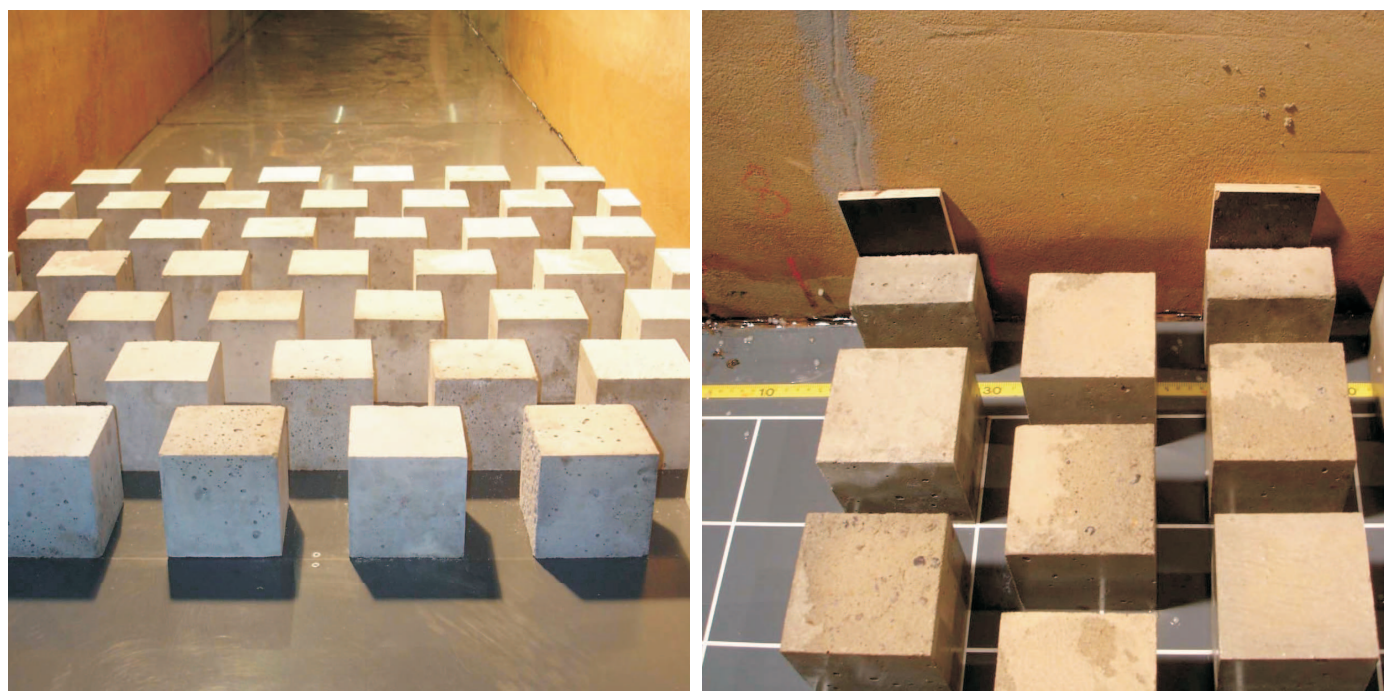

Fig. 5. Photographs of the MR element implementation. Left: Example of a staggered MR element configuration, Right: Half cubes used at the flume walls.
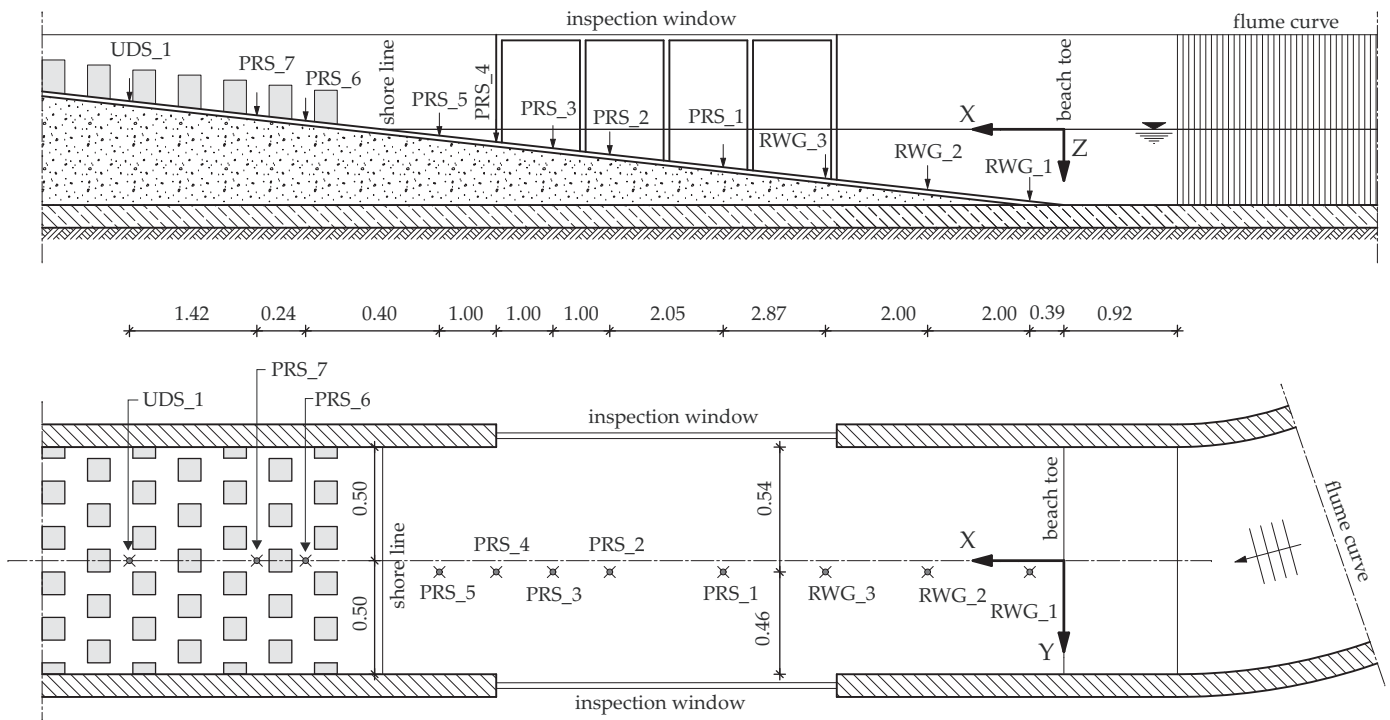

Fig. 6. Layout drawing of the laboratory instrumentation with used pressure sensors and wave gauges for the experimental set-up, abbreviations denote the following devices: PRS - pressure sensor, RWG - resistance wave gauge, UDS - ultrasonic distance sensor; for more than one device consecutive numbers are given, not to scale (units in metre), note that some sensors are not analysed in this paper.

the PVC board surface rectangularly pointing to the beach inclination.

The detection of the maximum wave run-up is of key importance in this study. Besides visual detection, beach parallel capacitive type wave gauges (Oumeraci et al., 2001) or camera-based techniques are feasible. Alternatively to these methods, in this study a drift-line-based approach is chosen to detect the maximum run-up of the waves. The basic idea resembles drift lines along natural beaches where deposited debris is one potential demarcation of the highest run-up of the incoming sea condition. Analogously, in this experiment run-up values are determined with measuring tape manually after each experiment. As tracer material a special artificial granulate was applied. It is a low-density polyethylene granulate of 0.91 to $0.94 \mathrm{~g} \mathrm{~cm}^{-3}$ density with an average diameter of 2 to $3 \mathrm{~mm}$. Even though the experiments were designed fully two-dimensional by observing the symmetry in longshore direction, measured run-up results vary along the flume width. The maximum run-up indicated by the applied tracers is not distributed along a straight line but parabolic with the apex in the flume axis. This phenomena arises from the fact that wall roughness of the plastering contributes to the 


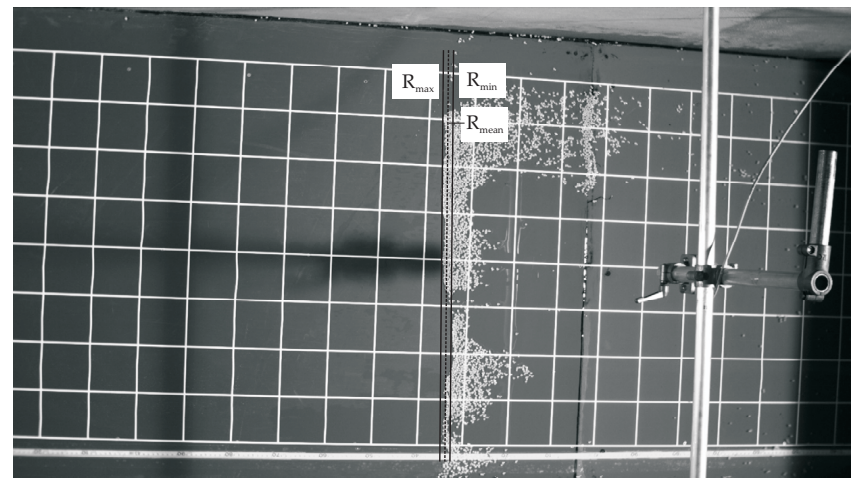

Fig. 7. Maximum wave run-up detection in the laboratory defined as the mean $\left(R_{\text {mean }}\right)$ of the lowest $\left(R_{\min }\right)$ and the highest maximum run-up $\left(R_{\max }\right)$.

energy dissipation in the boundary layer of the flume walls. The reported wave run-up, which is referred to in the following, is therefore defined as the mean of the lowest and the highest maximum run-up measured in each experimental run. Figure 7 exemplifies how the lowest $R_{\min }$ and the highest maximum run-up $R_{\max }$ were defined. In order to circumvent influences from wall effects, areas as close as $0.05 \mathrm{~m}$ to the flume walls were excluded from the run-up determination. After determination of minimal and maximal run-up, average values were recorded.

\subsection{Experimental procedure and data processing}

A typical experimental procedure encompasses the wave generation described in Sect. 3.1 along with the run-up measurements, the wave height and water depth measurements at various positions as well as the velocity measurements described in Sect. 3.3. After a long wave was generated it propagated along the flume and climbed up the sloping beach until its maximum run-up elevation was reached. Thereafter the particle velocity turned negative and the run-down phase followed.

Data processing aimed at converting, filtering, smoothing and decimating recorded signals. For some reasons an internal sampling rate of $1.0 \mathrm{kHz}$ was applied; thus decimation was accomplished by extracting every fiftieth data point from the signal subsequently after filtering and smoothing took place. Data were stored in a digital experimental notebook where in addition to the measured data, processed variables such as the configuration tag $\Gamma$, the vertical run-up $R_{\mathrm{v}, \min }$, $R_{\mathrm{v}, \max }$, the long- and cross-shore obstruction ratio $\psi_{\mathrm{ls}}, \psi_{\mathrm{cs}}$, the wave period $T$, crest $a_{\mathrm{cr}}$ and trough $a_{\mathrm{tr}}$ amplitudes and wavelength $L_{0}$ at the wavemaker, the wave number $k$, the frequency $\Omega$ and the surf similarity parameter $\xi_{0}$. Filtering with good results was obtained on the basis of the empirical mode decomposition (EMD) technique (Huang et al., 1998).

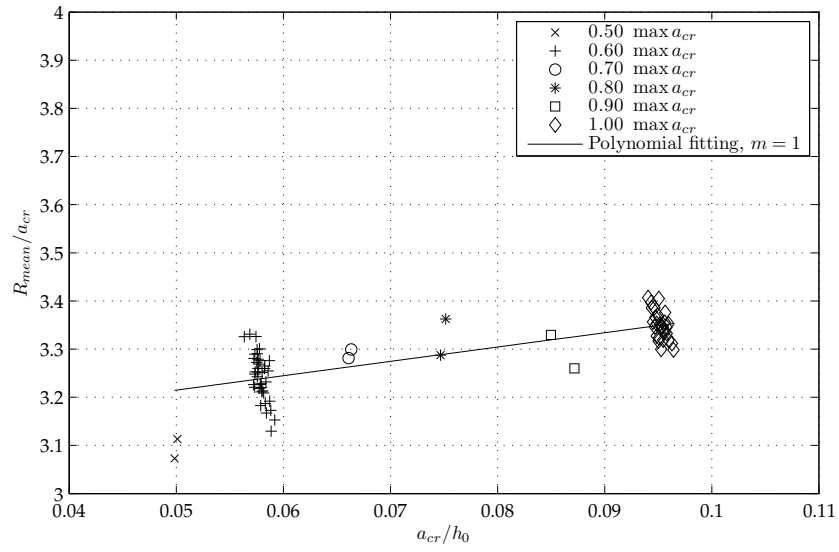

Fig. 8. Maximum relative run-up as a function of the nonlinearity $(\epsilon)$ of the waves depicted by the markers, a linear polynomial fit denotes the increase in maximum run-up with increasing nonlinearity.

Table 3. Summary of normalized run-up and relative differences with regard to configuration $\Gamma=1$ for MR element rows with $n=5 ; 10$, listed values base on the polynomial fitting curves.

\begin{tabular}{llllll}
\hline$\Gamma$ & $n$ & $\begin{array}{l}R_{\text {mean }} / a_{\mathrm{cr}} \\
\psi_{\text {ls }}=0.5\end{array}$ & $\Delta[\%]$ & $\begin{array}{l}R_{\text {mean }} / a_{\mathrm{cr}} \\
\psi_{\mathrm{ls}}=0.8\end{array}$ & $\Delta[\%]$ \\
\hline 1 & 5 & 3.30 & - & 2.80 & - \\
2 & 5 & 2.90 & 12.1 & 2.15 & 23.3 \\
3 & 5 & 3.01 & 8.8 & 2.32 & 17.1 \\
4 & 5 & 2.83 & 14.2 & 2.20 & 21.4 \\
\hline 1 & 10 & 3.20 & - & 2.70 & - \\
2 & 10 & 2.87 & 10.3 & 2.18 & 19.3 \\
3 & 10 & 2.93 & 8.4 & 2.38 & 11.9 \\
4 & 10 & 2.78 & 13.1 & 2.17 & 19.6 \\
\hline
\end{tabular}

\section{Results}

The wave run-up of single, sinusoidal waves was investigated by means of scale experiments. Basically wave height was varied and surf similarities between $\xi=7.69-10.49$ were achieved. Firstly 78 experiments were conducted to analyse the run-up on a plain 1 in 40 sloping beach without any surface-piercing MR objects. These results are addressed in Sect. 4.1. Subsequently, experiments were conducted that focus on the long-wave run-up reduction due to MR elements which were arranged in four different patterns on the shore, details are listed in Table 2. Resulting reduced run-up is described in Sect. 4.2. Additionally, in Sect. 4.4 it is qualitatively presented how the surface elevation evolves with and without MR elements on the shore in a longitudinal direction.

\subsection{Undisturbed run-up}

As outlined in Sect. B, the wave run-up directly relates to a number of dimensionless variables as presented in Eq. (B2). 


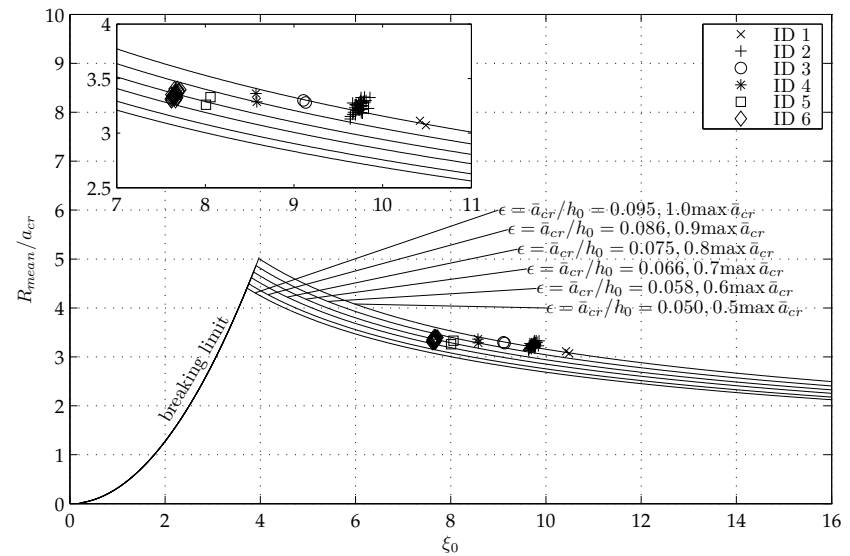

Fig. 9. Maximum relative run-up as a function of the surf similarity parameter $\left(\xi_{0}\right)$ depicted by the markers and according to the wave conditions applied, the theoretical breaking limit given by Eq. 5 and the theoretical run-up functions given by Eq. 3 (Madsen and Schäffer, 2010) based on the non-linearity $(\epsilon)$. The inset zooms to the experimental data.

In this research basically the wave nonlinearity $2 a_{0} / h_{0}$ was varied leading to the variation of surf similarity as mentioned before. Figure 8 depicts the maximum relative runup $R_{\text {mean }} / a_{\text {cr }}$ as a function of the nonlinearity $\epsilon=a_{\mathrm{cr}} / h_{0}$ of the investigated waves. Here, the maximum relative run-up is defined as the average of the measured run-up outlined in Sect. 3.3. The general trend of the measured data set is expressed by the polynomial fit of the degree $n=1$ which basically reduces to a linear function.

Since the overall aim was to investigate wave run-up reduction due to MR elements onshore, no further variations of the wave period $T$ and the beach slope $\tan (\beta)$ were accomplished in this research. In tendency, it becomes clear that an increasing nonlinearity results in increasing relative run-up. Yet, only non-breaking conditions were tested. It is also obvious that the relative run-up related to the positive crest amplitude is remarkably high. It ranges between $R_{\text {mean }} / a_{\mathrm{cr}}=3.1-$ 3.4. In order to check whether our data sets are consistent with existing research, Fig. 9 presents the maximum relative wave run-up in the framework of the surf similarity parameter (cf. Eq. 3 and Madsen and Schäffer, 2010). The maximum relative run-up, which is normalized by the positive amplitude at the wavemaker, decreases with an increasing surf similarity parameter $\xi_{0}$. The increase in non-linearity, which can be expressed as the ratio of the applied wave amplitude of the crest $a_{\mathrm{cr}} / h_{0}$, reduces the surf similarity of the applied wave condition at the beach under investigation. Higher non-linearity of the wave also indicates higher energy content. This finding underlines the statement of Madsen and Fuhrman (2008) after which critical flow depth and flow velocities occur for surf similarity in the order of $\xi_{0}=3-6$ and in turn require relatively mild beach slopes.
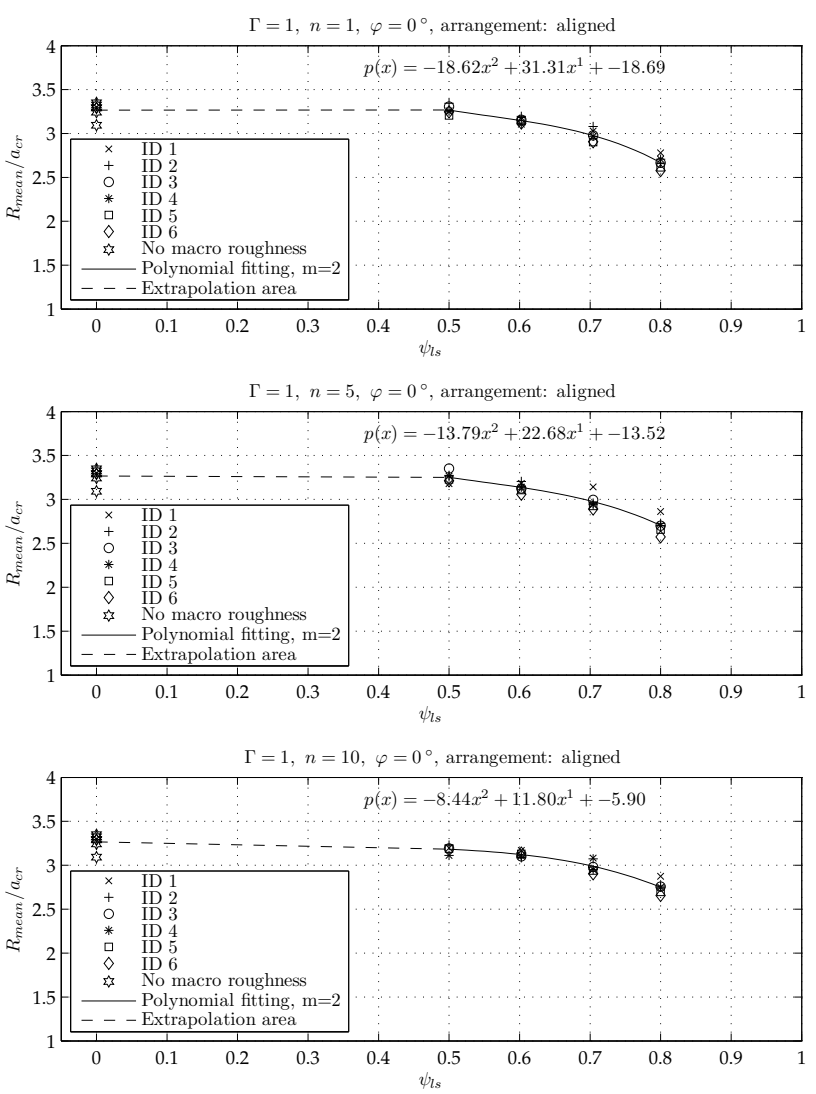

Fig. 10. The relative wave run-up $\left(R_{\text {mean }}\right)$ as a function of the longshore obstruction ratio $\left(\psi_{\mathrm{cs}}\right), \Gamma=1$. The experimental data are fitted to a polynomial of degree $m=2$ and the equations are given according to the investigated number of MR rows $n=1,5,10$.

The resulting measurements depicted by the point clouds are in good agreement with the analytical framework. Yet, it is apparent that the results do not perfectly fit the expected analytical behaviour even though the results already indicate that the theory and the functional relation of the nondimensional terms are well established. The analytical approach fully neglects the influence of roughness and even though the experiments aim at eliminating roughness influences to the greatest extent, energy losses due to roughness influence are still existent. From the degree of agreement between the experimental data and the analytical approach it can thus be reasoned that the experimental set-up is in principal suitable to reproduce long-wave motion in scaled models and in the following it shall be demonstrated how MR elements contribute to reduced long-wave run-up quantitatively.

\subsection{Run-up reduction}

Cross $\left(\psi_{\mathrm{cs}}\right)$ and long-shore obstruction ratios $\left(\psi_{\mathrm{ls}}\right)$ as well as the MR configuration $\Gamma$ was found to influence run-up reduction of long waves climbing up a plain, sloping beach as described in Sect. 2 and the dimensional analysis presented in 
the Appendix. According to Table 2 four MR configurations were tested and results are presented in this section subsequently. Additional plots are presented in the Annex. Firstly, the relative run-up of long waves normalized by the positive wave amplitude at the wavemaker is shown in Fig. 10 as a function of the long-shore obstruction ratio (Eq. 8) where long-shore obstruction ratio of unity denotes full obstruction of the beach section. Equally, a zero long-shore obstruction ratio indicates that no obstacles are present on the beach and those cases are represented in Fig. 10 by the star symbol. As shown, not much difference in relative run-up is found between $\psi_{\mathrm{ls}}=0.5$ and the limiting case of $\psi_{\mathrm{ls}}=0.0$

The MR configuration $\Gamma=1$ comprises MR elements in aligned arrangement with non-rotated elements. The resulting run-up reduction can generally be described by a downward opening parabolic function. Note that two of the experiments were excluded from the analysis because measured run-up appeared to be non-physical. Four different longshore obstruction ratios were tested. Long-wave run-up diminishes with increasing $\psi_{1 \mathrm{~s}}$. It appears that the influence of the incident wave amplitude indicated by the marker symbols tends to increase with an increasing long-shore obstruction ratio. Higher incident wave amplitudes result in higher water levels in the vicinity of the macro-roughness area. A reason for this finding could be that higher velocities in between the MR openings result in higher energy exchange between the predominant inland-directed flow and the calmed areas in the back of MR elements; thus leading to increasing energy dissipation. This observation agrees with the findings of Goto and Shuto (1983) who investigated the effects of wooden pillars exposed to a steady flow and similarly reported momentum exchange between the main flow and eddies in the back of their obstacles. Figure 10 also indicates that the number of MR element rows $(n)$ has a much smaller influence on the maximum run-up reductions. For values of $\psi_{\mathrm{ls}}=0.8$ only marginal differences exist between the relative run-up reduction $\left(R_{\text {mean }} / a_{\mathrm{cr}}\right)$. Yet, it appears that the scatter of the measured run-up slightly increases to some extent, which could be attributed to an increase in turbulence when the flow interacts with a higher number of MR element rows.

According to the tabulated results presented in Table 3 the highest run-up reduction is achieved by MR configuration $\Gamma=2$ which depicts the aligned, rotated case (cf. Table 2). This configuration leads to additional run-up reduction of $21.3 \%$ for $\psi_{\text {ls }}=0.8$ when $n=5$ MR element rows are tested. This reduction slightly decreases for the case with $n=10$ MR element rows which at first contradicts the statement that energy reduction increases with increasing number of MR element rows. Although here, this opposed trend is rather related to the scatter of data that leads to variations in the polynomial fitting curves applied for the summary table. The influence of the MR angle is further described and discussed in Sect. 4.3.
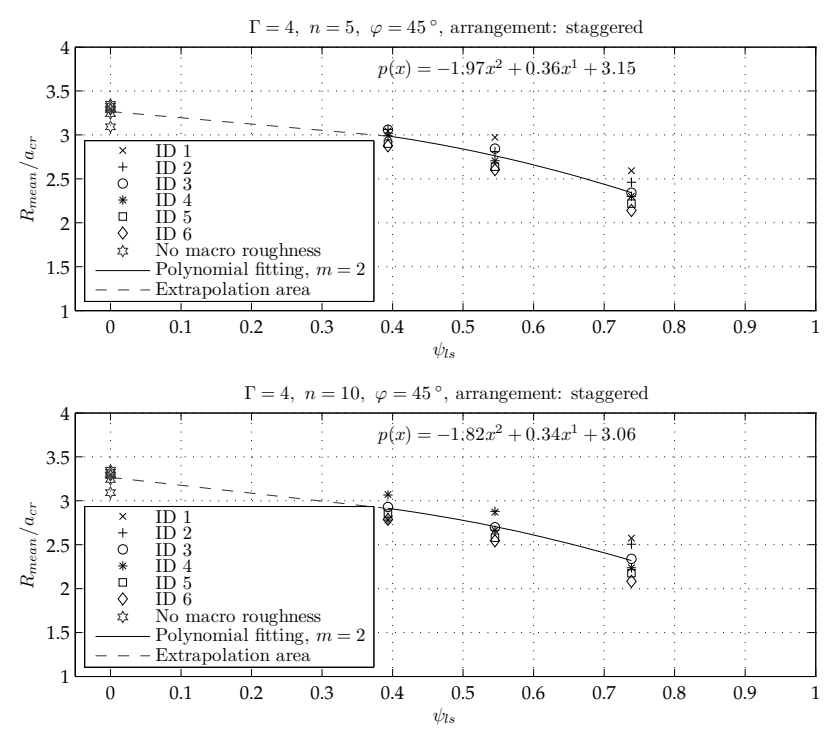

Fig. 11. The relative wave run-up ( $\left.R_{\text {mean }}\right)$ as a function of the longshore obstruction ratio $\left(\psi_{\mathrm{ls}}\right), \Gamma=4$. The experimental data are fitted to a polynomial of degree $m=2$ and the equations are given according to the investigated number of MR rows $n=5,10$.

In order to incorporate the non-dimensional variable crossshore obstruction ratio $\left(\psi_{\mathrm{cs}}\right)$ it is convenient to define an additional non-dimensional variable that accounts for the entire horizontal obstruction ratio. It may read

$\psi_{2-\mathrm{D}}=\psi_{\mathrm{cs}} \psi_{1 \mathrm{~s}}$.

Equation (9) relates the long- and the cross-shore obstruction ratio. While the long-shore obstruction ratio resides between zero and unity, the cross-shore obstruction ratio, by definition, reaches unity if only one macro-roughness row is considered and decreases with a growing number of macroroughness element rows. For one MR element row the product of $\psi_{\mathrm{cs}}$ and $\psi_{\mathrm{ls}}$ reduces to the long-shore obstruction ratio $\left(\psi_{\mathrm{ls}}\right)$, whereas it grows with an increasing number of element rows. It has to be noted that the 2-D obstruction ratio is based on the assumption that the street widths in the cross- and long-shore direction are equal. As an example, Fig. 12 presents the normalized run-up as a function of the two-dimensional obstruction ratio $\psi_{2-\mathrm{D}}$ according to Eq. (9) for the case of $\Gamma=2$ with rotated elements in an aligned arrangement.

The upper panel of Fig. 12 is identical to those results where $\Gamma=2$ and $n=1$ plotted only as a function of $\psi_{\text {ls }}$ while the lower two panels reveal the functional dependency on the two-dimensional obstruction ratio as defined by Eq. (9). It is obvious that with increasing MR element rows $(n)$ the values of 2-D obstruction ratio ( $\left.\psi_{2 \text {-D }}\right)$ approach unity. As clearly seen, a 2-D obstruction ratio is a non-linear variable and here it is defined so as to acknowledge that the run-up reduction effect is most pronounced for few MR element rows, whereas this effect diminishes with increasing number of MR element rows. 

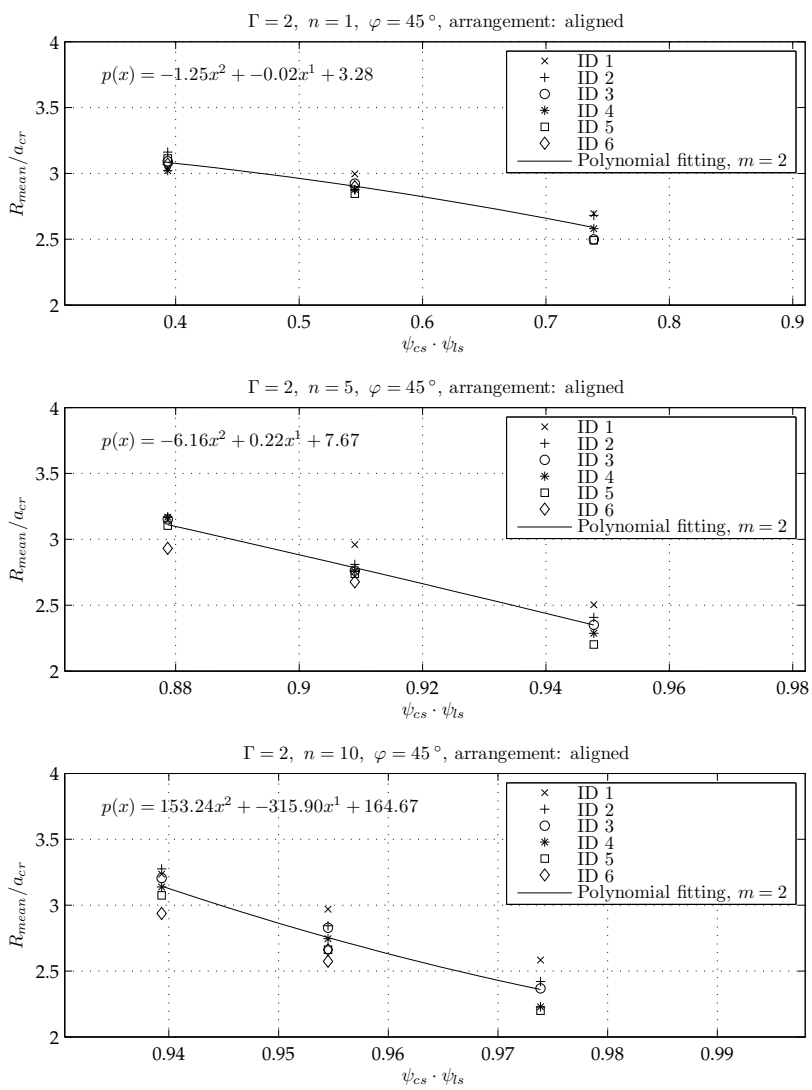

Fig. 12. The relative wave run-up $\left(R_{\text {mean }}\right)$ as a function of the crossshore obstruction ratio $\left(\psi_{\mathrm{cs}}\right)$ times the long-shore obstruction ratio $\left(\psi_{1 \mathrm{~s}}\right), \Gamma=2$. The experimental data are fitted to a polynomial of degree $m=2$ and the equations are given according to the investigated number of macro-roughness rows $n=1,5,10$.

From an engineering perspective it is preferable to either yield empirical equations or derive nomograms which are suitable to predict the reduced run-up due to a given MR configuration in comparison with the undisturbed case. Besides the specific MR element configuration, it is the longshore obstruction ratio that basically dominates the run-up reducing effect of the investigated MR elements as a function of the cross-shore obstruction ratio, as outlined above. On that basis it is convenient to focus on the dominating long-shore obstruction ratio $\left(\psi_{\mathrm{ls}}\right)$ to deduce conclusions from the experimental findings. Figures 13 and 14 illustrate the relation of the relative run-up $\left(R_{\text {mean }} / a_{\mathrm{cr}}\right)$ to the surf similarity parameter $\left(\xi_{0}\right)$ within the analytical framework of Madsen and Schäffer (2010) for the MR configurations $\Gamma=2,4$. Nomograms referring to the configurations $\Gamma=1,3$ are presented in the annex for completeness. The reduced relative run-up according to the MR elements on the shore is expressed by means of the long-shore obstruction ratio and is plotted as a error bar line where the line denotes the averaged run-up of the cases $n=1, n=5$ and $n=10$. The error bars mark the standard deviation of the measured relative run-up. Generally, a smaller relative run-up is associated with a higher number of macro-roughness element rows. The relative run-up associated with the long-shore obstruction ratio slightly decreases with an increasing non-linearity of the applied waves, which is most likely contributed to greater momentum exchange within the MR element area. Six error bars for each long-shore obstruction ratio indicate those wave conditions tabulated in Table 1.

For both nomograms presented in Figs. 13 and 14, the reduction of the relative run-up decreases slightly with decreasing surf similarity $(\xi)$. The reduction of the relative run-up compared to undisturbed conditions is less significant for a long-shore obstruction ratio of $\psi_{1 \mathrm{~s}}=0.393$; yet, it appears that the maximum run-up tends to zero when the long-shore obstruction ratio is further increased. Standard deviation of measured relative run-up is rather small indicating that most of the experimental results are fairly repeatable. Secondly, it can be observed that the relative run-up again decreases with an increase in non-linearity, which is probably contributed to the growth in momentum exchange when waves of higher non-linearity interact with the MR elements. Higher turbulence production is assumed to affect the increase in run-up reduction.

\subsection{Influence of the MR angle}

In contrast to the aligned MR configurations, Fig. 11 depicts MR configuration $\Gamma=4$ where MR elements are arranged in a staggered manner and rotated by the angle $\varphi=45^{\circ}$. The functional dependency between normalized run-up and long-shore obstruction ratio is similar to the aligned, nonrotated configuration. A parabolic polynomial is also suitable to fit the measured data. The extrapolated region between $\psi_{\mathrm{ls}}=0.5$ and 0.0 is indicated by a dashed line while the runup results without consideration of obstacles on the beach are represented by some stars. Yet, the run-up reduction is higher than in the non-rotated cases. A summary of the results and the comparison of investigated MR configurations is presented in Table 3 .

In comparison with non-rotated MR configuration $\Gamma=1$ a substantial additional run-up reduction could be found for configuration $\Gamma=4$ (cf. Fig. 4 , right panel). It appears that for cases with $n=5 \mathrm{MR}$ element rows in staggered, rotated configuration, the normalized run-up decreases by $4.2 \%$ for $\psi_{\mathrm{ls}}=0.5$ and by $21.4 \%$ for $\psi_{\mathrm{ls}}=0.8$, while in case of $n=10$ MR element rows those reductions are $13.1 \%$ for $\psi_{\mathrm{ls}}=0.5$ and $19.6 \%$ for $\psi_{\mathrm{ls}}=0.8$, respectively. Additionally, some scatter is introduced into the data in the case of $\Gamma=4$. This fact underlines the hypotheses that the run-up flow experiences higher turbulence production in this case. Additionally, the approaching wave front is obliquely reflected at every even MR element row directing the wave front to the back side of the uneven MR element rows and thus leading to additional energy dissipation through vortex formation. 


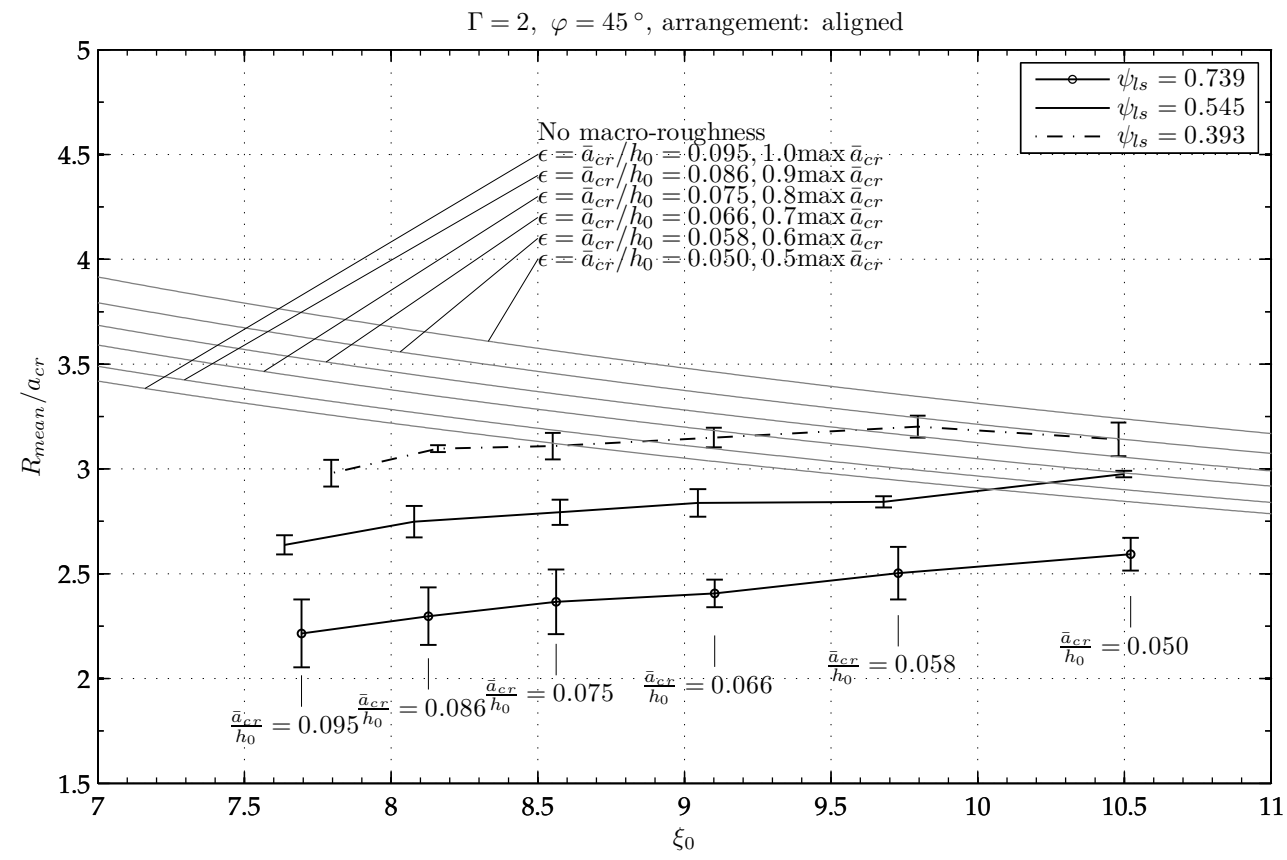

Fig. 13. The relative wave run-up $\left(R_{\text {mean }} / a_{\mathrm{cr}}\right)$ as a function of the surf similarity parameter $\left(\xi_{0}\right), \Gamma=2$. The experimental data are plotted according to the individual long-shore obstruction ratio. The error bars indicate the variation of the number of macro-roughness element rows. The grey parallel graphs indicate the relative run-up without the interaction with macro-roughness. The non-linearity of the applied waves is indicated as text which always refers to all error bars in the vertical above.

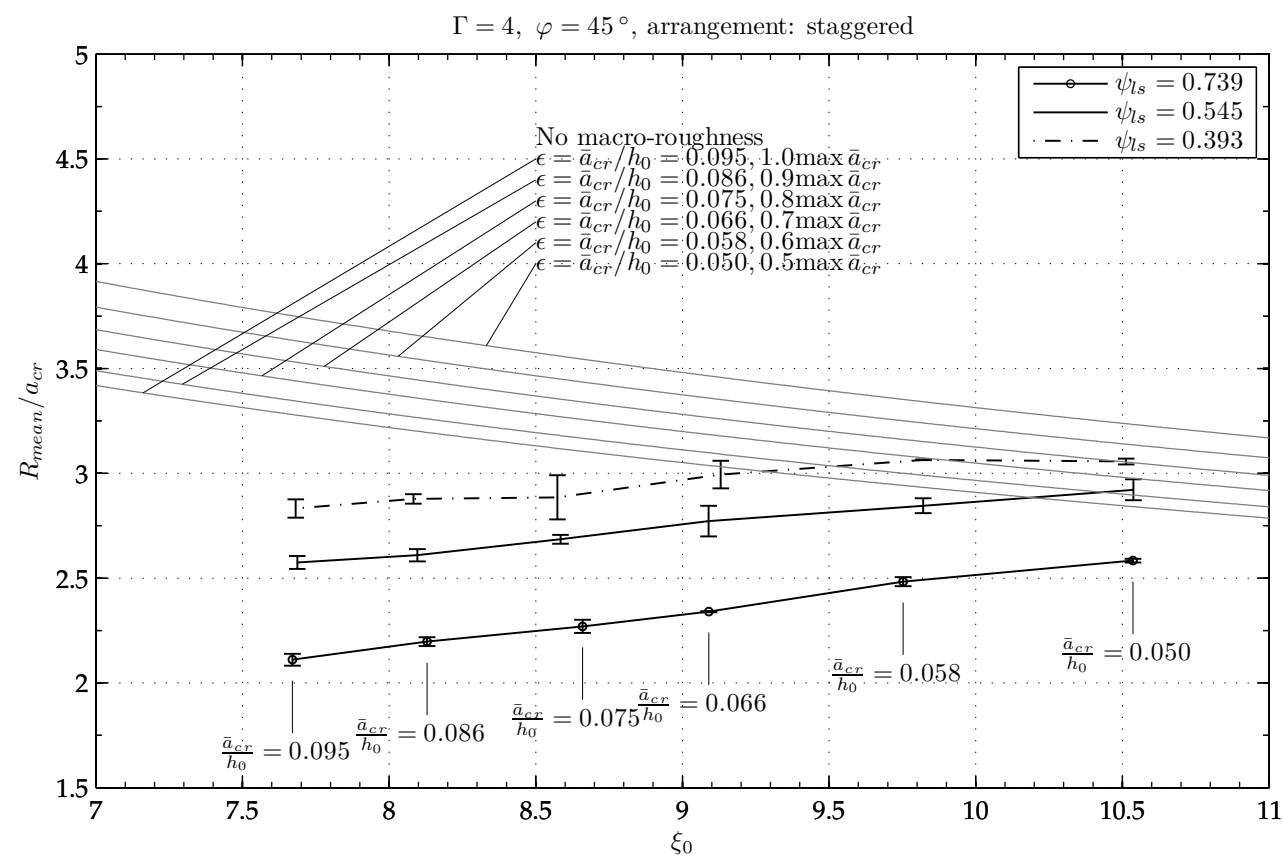

Fig. 14. The relative wave run-up $\left(R_{\text {mean }} / a_{\mathrm{cr}}\right)$ as a function of the surf similarity parameter $\left(\xi_{0}\right), \Gamma=4$. The experimental data are plotted according to the individual long-shore obstruction ratio. The error bars indicate the variation of the number of macro-roughness element rows. The grey parallel graphs indicate the relative run-up without the interaction with macro-roughness. The non-linearity of the applied waves is indicated as text which always refers to all error bars in the vertical above. 

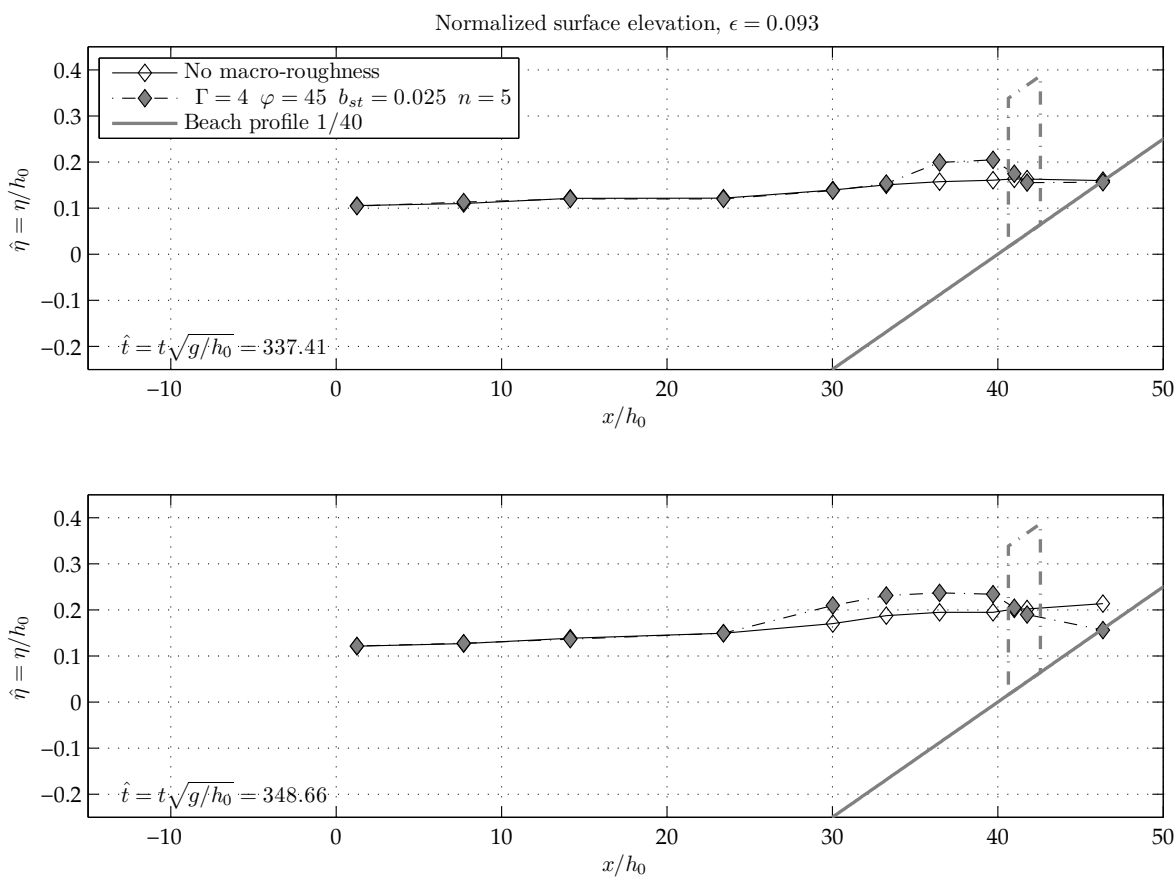

Fig. 15. Comparison of the normalized surface elevation for a sinusoidal wave with $\epsilon=0.093$ at $\hat{t}=337.41$ and $\hat{t}=348.66$ with and without the presence of macro-roughness elements. The macro-roughness element configuration is specified by $\Gamma=4, \varphi=45^{\circ}, b_{\mathrm{st}}=0.025$ and $n=5$. Surface elevation and spatial coordinates are normalized by the invariant water depth $\left(h_{0}\right)$. The dash-dotted line depicts the macroroughness element area.
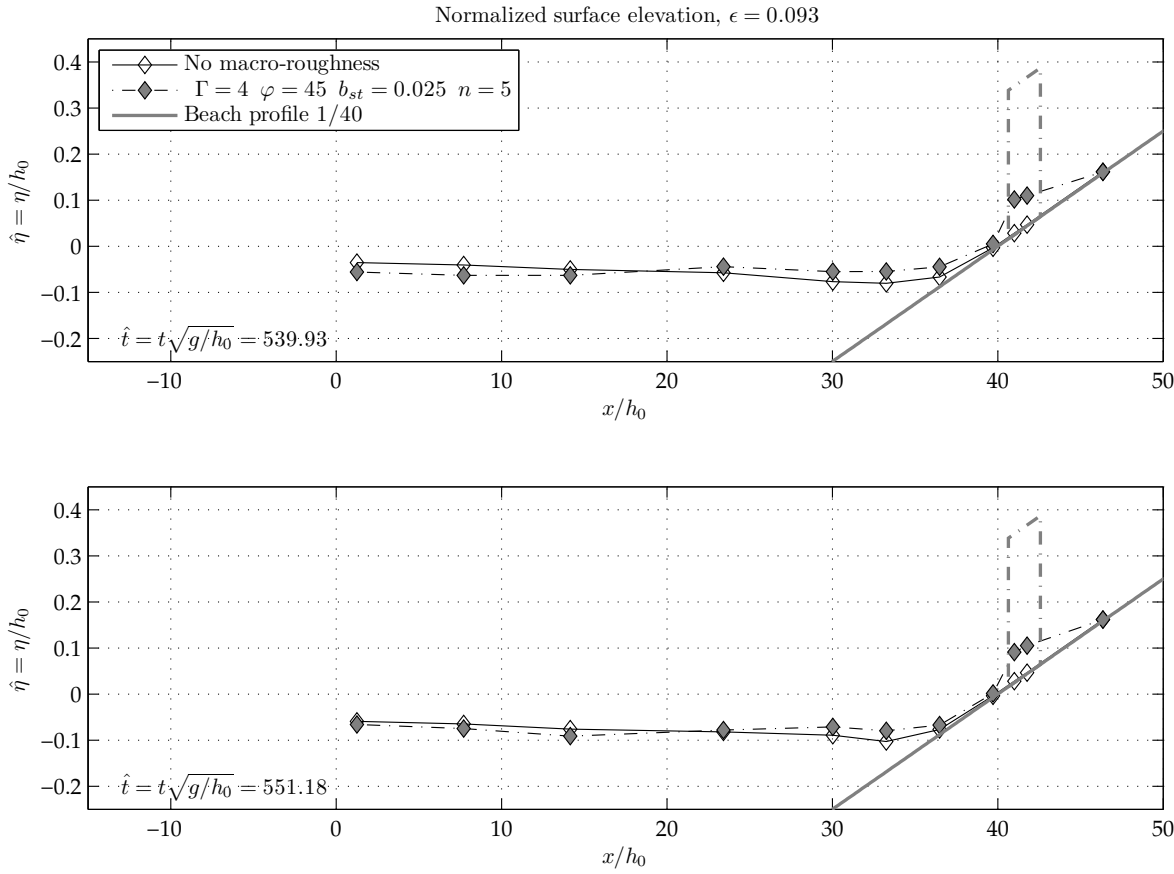

Fig. 16. Comparison of the normalized surface elevation for a sinusoidal wave with $\epsilon=0.093$ at $\hat{t}=539.93$ and $\hat{t}=551.18$ with and without the presence of macro-roughness elements. The macro-roughness element configuration is specified by $\Gamma=4, \varphi=45^{\circ}, b_{\mathrm{st}}=0.025$ and $n=5$. Surface elevation and spatial coordinates are normalized by the invariant water depth $\left(h_{0}\right)$. The dash-dotted line depicts the macroroughness element area. 
As listed in Table 3, cases $\Gamma=2$ (aligned, $\varphi=45^{\circ}$ ) and 4 (staggered, $\varphi=45^{\circ}$ ) always depict higher run-up reductions compared with the reference case $\Gamma=1$. In our opinion, this substantiates the conclusion that the influence of block angle is stronger than the influence of aligned or staggered arrangement. This result holds true for either 5 or 10 rows of MR elements (cf. Sect. 5).

\subsection{Longitudinal evolution of surface elevation}

Finally, the longitudinal evolution of the free surface elevation of the undisturbed long-wave run-up is compared to the MR configuration $\Gamma=4$, a staggered and rotated configuration, with $\psi_{1 \mathrm{~s}}=0.739$ and $n=5 \mathrm{MR}$ element rows. Here, the qualitative influence of MR elements configuration to the spatial distribution of the water level at distinct time steps should be assessed. Out of the sequence of available time steps of the wave evolution along the beach wedge, Fig. 15 depicts the situation during wave run-up while Fig. 16 focuses on the draw-down phase. Time is given non-dimensionally with reference to the beginning of the wave generation at the wavemaker; thus, non-dimensional time $\hat{t}=t \sqrt{g / h_{0}}$ relates to the total time for the wave needed to propagate along the horizontal bottom section and climbing up the 1 in 40 sloping beach. Both figures illustrate the development of the surface elevation profile along the beach wedge. The normalized surface elevation $\hat{\eta}=\eta / h_{0}$ is given as a function of the non-dimensional horizontal coordinate $\hat{x}=x / h_{0}$. The position and the height of the obstacle area is given by the dash-dotted grey lines while the beach surface is presented by the full grey line. A wave with a non-linearity of $\epsilon=0.093$ is used. Generally, three qualitative phases can be determined during the evolution of the wave. First of all the initial draw-back of the water, which is due to the leading depression wave character, characterizes the wave evolution. In this phase no significant differences can be found for the cases with and without MR elements. In a second phase when the water surface elevation is rising on the beach, in tendency higher water levels are determined for the obstructed case. Thirdly, during the draw-down of the long wave the situation inverts and the surface profile is lower for the case with MR elements present. The flow of water which is in-between and behind the MR area is retarded significantly (Fig. 16).

An interesting feature is demonstrated in Fig. 15. The approaching wave tongue collides with the first MR element row and a shock wave is formed which propagates seawards. This flow feature is observed for all investigated long-shore obstruction ratios and for all MR configurations. The height of the shock wave qualitatively depends on the long-shore obstruction ratio, though this dependency has not been investigated in detail in this research. The front of the initiated reflection wave is comparable with a monoclinal rising wave which though rapidly varies during its seaward propagation. In the presented case the surface gradient of the positive surge, whose front is initially steep, decreases rapidly and it flattens out noticeably (lower panel of Fig. 15). The situation inverts as soon as the long wave starts the drawdown process (Fig. 16). In the vicinity of the MR elements the undisturbed case faces higher water levels than in the case with MR elements. This is a direct result of the effect of the MR elements causing decreasing maximum wave run-up, since obstacles are causing partial reflections of the shoreward transported wave energy. Finally, an additional feature appears within the MR element area. There, the water levels are higher with MR elements compared to the undisturbed case. This is due to the fact that the volume of water which at this time is situated in-between and behind the obstacles is retarded significantly and is only displaced during the drawdown phase with a notable time lag. In the case of MR it is apparent that the negative, seaward directed surface gradient in the vicinity of the obstacles is considerably higher than that without obstacles. In consequence, the flow velocities are qualitatively increased compared to the undisturbed run-up.

\section{Discussion}

Section 4 presents experimental results which were obtained to address the question of how MR elements on a shore influence the run-up of a long wave approaching a plain, sloping beach. Based on the parameters long- and crossshore obstruction ratio as well as on four different MR element configurations run-up reductions were determined compared with an analytical approach after Madsen and Schäffer (2010). Prototype conditions were approximated by means of a plain, sloping beach and MR elements consisting of concrete cubic blocks representing beachfront development with close proximity the the shoreline. Instead of an unstructured urban building pattern, regular MR element pattern were chosen. Additionally, the three-dimensional prototype character was substituted by a 2-D scale model, since laboratory space was limited. Yet, this 2-D approach provides reasonable results for prototype conditions in case that homogeneity in long-shore direction can be assumed. Larger deviations are likely when up-scaled results are going to be utilized to predict run-up extents of tsunami in coastal regions where strongly inhomogeneous urban patterns exist. However, the presented results are considered suitable for the calibration of analytical or numerical models that also aim at predicting the energy dissipation and run-up reduction due to beachfront development. Long waves were generated by means of a novel long-wave generator which utilized high-capacity pumps under the control of an industrial controller (Goseberg, 2012; Goseberg et al., 2013). Due to limited laboratory space and some related restrictions, wave propagation was through a $180^{\circ}$ bend. Therefore, the question arises whether this laboratory setting negatively influences the quality and shape of the applied wave conditions. In this regard, Goseberg (2011) researched how transverse and 
propagation-wise velocity cross profile evolved at times of maximum positive or negative flow. It was found that rather uniform vertical velocity profiles developed which is in accordance with the long-wave theory and that, more importantly, transverse velocity components inside the flume bend were marginal, so that no direct influence on the wave propagation is expected.

The basic flow features which were observed in the course of the run-up and draw-down phase of the wave climbing up the beach and interacting with the MR elements consist of acceleration and deceleration due to sudden narrowing and widening in between the MR element area. This process increases with reduction of long-shore obstruction ratio and with increasing non-linearity of the incident waves. These features directly influence the maximum run-up that was under investigation. These findings are in close agreement with previous findings for steady-state flows. For example, Soares-Frazão et al. (2008) qualitatively found the same flow pattern (sudden narrowing, widening and deceleration) in the case of a flood wave impinging an urban settlement of houses which are arranged in an aligned and staggered configuration. Similar findings were reported by Goto and Shuto (1983) and Soares-Frazão and Zech (2008).

Besides the fundamental flow features that were determined, four different MR element configurations were tested with varying number of obstacle rows. A summary of absolute run-up and differences between those variations is presented in Table 3. It appears that absolute run-up reduction for a given obstruction ratio depends on the kind of MR element arrangement (i.e. aligned or staggered). Aligned and staggered arrangements with identical angle of rotation yield differences of 8.4 to $8.8 \%$ for $5 \mathrm{MR}$ rows and 11.9 to $17.1 \%$ for $10 \mathrm{MR}$ rows. Yet, especially in case of the aligned configuration $(\Gamma=1,2)$ the angle of rotation seems to have a greater contribution to the overall run-up reduction compared with the staggered configuration $(\Gamma=3,4)$ where difference are less dominant. This effect is clearly seen with the increasing number of MR element rows. An increasing effect of MR element rotation angle to the overall run-up reduction is also observed with increasing obstruction ratio which can be substantiated by differences for configuration $\Gamma=1,2$ between $\psi_{1 \mathrm{~s}}=0.5,0.8$. Differences in this case are almost doubled from $12.1 \%$ to $23.3 \%$. A likely explanation of this fact is that an angle of $\varphi=45^{\circ}$ results in much greater local momentum deflection at the MR elements than in non-rotated cases. The momentum deflection in turn leads to greater turbulence generation in the zone where two opposing currents are colliding with each other and therefore a larger amount of energy is dissipated. Due to the greater energy dissipation, less energy is maintained in the run-up tongue resulting in smaller overall run-up values. Hence from the results obtained by an comparison of effects due to angle of rotation and due to MR element configuration it is apparent that the angle of rotation stronger influences the overall run-up reduction than the distinction of aligned or staggered configuration.
Nomograms have been elaborated on the basis of the analysed experimental research. Those nomograms reflect the ability of the tested MR element configurations to reduce the overall run-up of the researched waves for a 1 in 40 sloping beach. Contrary to prototype conditions, beachfront development was idealized by concrete cubic blocks which were arranged in a regular pattern. This approach significantly differs from prototype development in terms of structuring, where houses and infrastructure is mostly randomly distributed. Nevertheless, the roughness effect to an incoming flow which is either exposed to a randomly build or a structured development is maintained by defining cross- and longshore obstruction ratios. This approach is based, of course, on the assumption that roughness effects considered over a larger onshore area cancel out local variability in MR element distribution. In order to compare the obtained results with a realistic prototype situation it is thus under this assumptions possible to check for the given obstruction ratios of an area under research. With those obtained values one might consider the nomograms for estimating possible runup reduction; this method offers a rough estimation at least for beach slopes within the investigated range. Practically, the presented results could be applied to a given sample setting in the following steps;

- Determination of natural shelf or beach slope and check of applicability to the presented results obtained from 1 in 40 beach slope experiments.

- Determination of cross- and long-shore obstruction ratios through evaluation of Eqs. (6) and (8) (definition of horizontal obstruction ratios) along some chosen transects parallel and orthogonal to the shoreline Classification of the given beachfront development.

- Selection of most applicable arrangement of the building setting with respect to arrangements $\Gamma=1-4$.

- Choice or review of wave parameters of a potential tsunami at the particular location, e.g. wave height, duration or period and water depths in order to calculate a corresponding surf similarity parameter.

- Utilization of the associated nomogram (determined surf similarity parameter and parameters of the classified beachfront development) by reading off the undisturbed tsunami. run-up as well as the run-up reduction predicted by the experimental results

The above procedure may allow for estimating zones safe to tsunami inundation for simplified cases and a subsequent check whether existing evacuation procedures (e.g. extent of evacuation) are suitable to assure personal safety of the evacuees. Thus, it is of course undisputed to additionally apply depth averaged numerical modelling for areas of high risk. 
Besides analysing the overall run-up reduction due to the presence of MR elements Figs. 15 and 16 depict some characteristic stages of the wave run-up and subsequent drawdown process in the vicinity of the first MR row. Note that the presented surface elevations show snapshots of the surface elevation. The overall (total) run-up could not be determined from the figures presented above. Compared with non-obstructed conditions, a shock wave is generally generated at the first row of obstacles which starts propagating back offshore as soon as the wave tip reaches the MR elements. This shock wave is considered to reflect some of the incoming wave energy though it has to be further researched quantitatively what contribution the beachfront development has to the overall reflection coefficients. In addition, the wave is retarded in a later stage of the run-up process and a volume of water is held back, since it is supposed to flow back to the sea through the opening between the MR elements in the first row. This is of great importance with respect to prototype conditions since it confirms the common belief that receding waters draw back slower in the vicinity of build environment than in regions where open land is found at the coastline.

\section{Conclusions and outlook}

The experiments reported herein address the problem of determining the reduction of maximum tsunami run-up on a 1 in 40 plane beach when the run-up process is disturbed by beachfront development in close proximity of the shoreline. The resistance of urban structures on the beach is modelled by means of MR elements made of cubic concrete blocks. The experimentally determined relative run-up of single sinusoidal waves on the plane beach without MR elements agrees well with an analytical approach by Madsen and Schäffer (2010). For the first time this theoretical approach is successfully validated by experimental means. The relative run-up of the waves under consideration is significantly influenced by the presence of MR elements onshore. As a result, nomograms are presented to facilitate the determination of the relative run-up reduction for four different MR element configurations, various long- and cross-shore obstruction ratios and a range of wave non-linearities. Simple yet idealized predictions of the reduction of long waves due to MR element configurations are therewith made possible. The experimental data sets of long-wave run-up are also capable to be utilized for the calibration and validation of numerical models.

It belongs to the character of laboratory idealizations that some aspects of the prototype process are still neglected. Among these aspects are influences stemming from the collapse of buildings, the transport of sediment and debris, the volumetric disequilibrium between solid blocks (in the present model) and common hollow buildings (in prototype), three-dimensional influences of river estuaries or heterogeneous existing developments, different building orientations and dimensions, the overflow of developments and spatially or temporally varying surface gradients. Moreover, the presented material is believed to owe the potential to facilitate future modelling approaches of beachfront development, though it is beyond the intention of this paper. The above mentioned aspects remain untreated and further laboratory work is needed to elucidate those additions to the interaction process of long waves and beachfront development.

\section{Appendix A}

\section{Additional nomograms}

Some more nomograms are provided in this section that add information about the remaining MR configurations $\Gamma=1,3$ for the sake of completeness.

\section{Appendix B}

\section{Dimensional analysis and laboratory effects}

\section{B1 Dimensional analysis}

Dimensional analysis was often utilized in the past to optimise experimental research. It is an engineering tool that allows to express and describe physical processes by means of dimensionless terms after the dependent variables for the process have been deduced and delineated (Yalin, 1971). By means of the theorem of Buckingham it becomes possible to reduce an equation of the form $f\left(x_{1}, x_{2}, \ldots, x_{n}\right)=0$ containing $n$ physical variables $x$ with a dimension matrix of order $r$ into an equation of the form $F\left(\Pi_{1}, \Pi_{2}, \ldots, \Pi_{n-r}\right)=0$ by recasting into dimensionless $\Pi$ terms. The dimensionless variables $\Pi$ are composed of power products of the former dimensional variables $x$. Undisturbed wave run-up was investigated by various authors (i.e. Hunt, 1959). Dimensional analysis for this problem was addressed in detail by Müller (1995) who derived dimensional analysis for the problem of impulsive wave propagation and run-up in alpine lakes induced by rock fall. Limiting the problem to two-dimensionality, neglecting model, scale as well as frictional effects, relative run-up might be related to the following dimensional variables:

$f(\underbrace{g, \varrho, \nu, \varsigma}_{\text {universal properties }}, \underbrace{a, T, \beta, c}_{\text {plain wave run-up }}, \underbrace{b_{\mathrm{mr}}, b_{\mathrm{st}}, n, \varphi, \Gamma}_{\text {MR related }})=0$,

where $g$ is gravitational acceleration, $\varrho$ is density of the fluid, $v$ is kinematic viscosity, $\varsigma$ is surface tension. $H / 2=a$ describes wave amplitude which for sinusoidal waves equals height $H / 2$ of a wave with period $T$ and with propagation speed $c$ running up on a beach with slope $\tan \beta$. A third group of variables accounts for wave structure interaction due to 


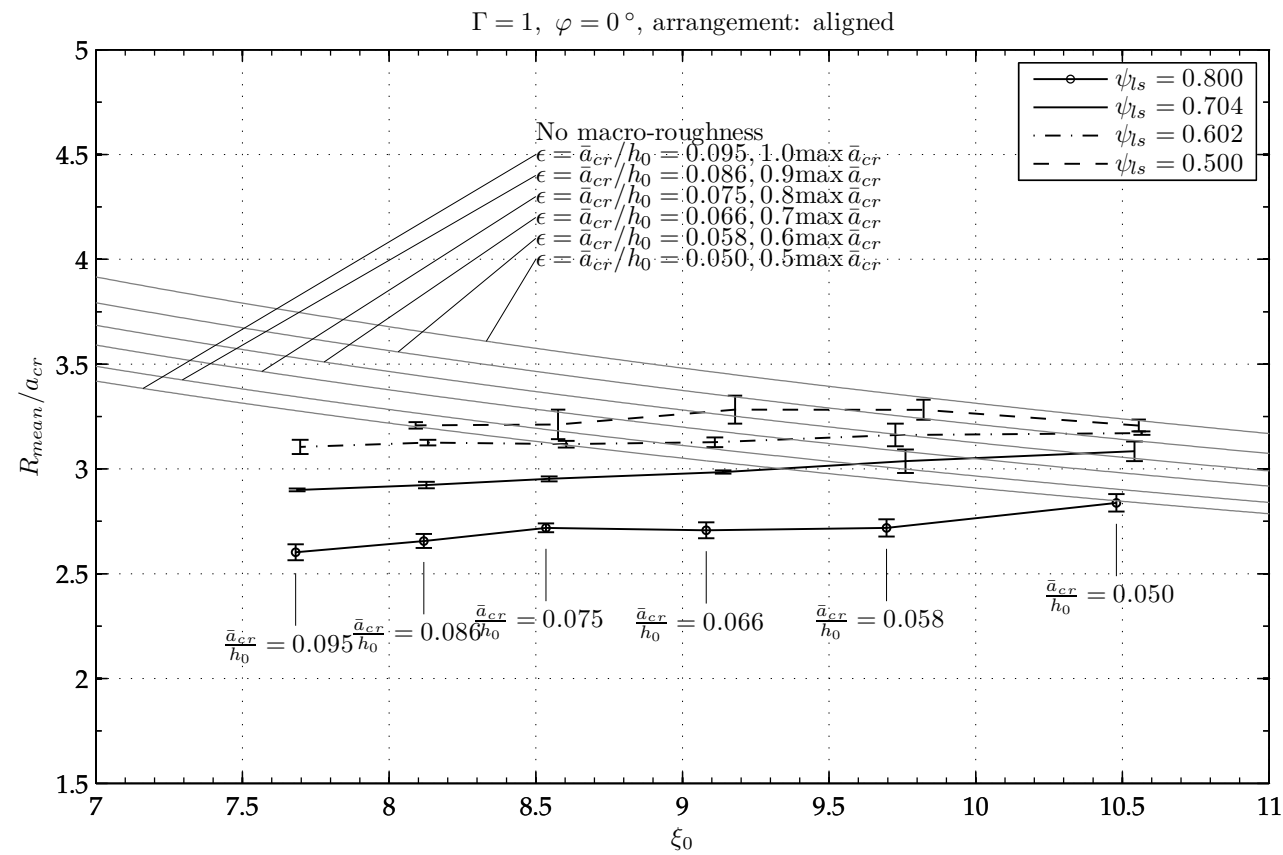

Fig. A1. The relative wave run-up $\left(R_{\text {mean }} / a_{\mathrm{cr}}\right)$ as a function of the surf similarity parameter $\left(\xi_{0}\right), \Gamma=1$. The experimental data are plotted according to the individual long-shore obstruction ratio. The error bars indicate the variation of the number of macro-roughness element rows. The grey parallel graphs indicate the relative run-up without the interaction with macro-roughness. The non-linearity of the applied waves is indicated as text which always refers to all error bars in the vertical above.

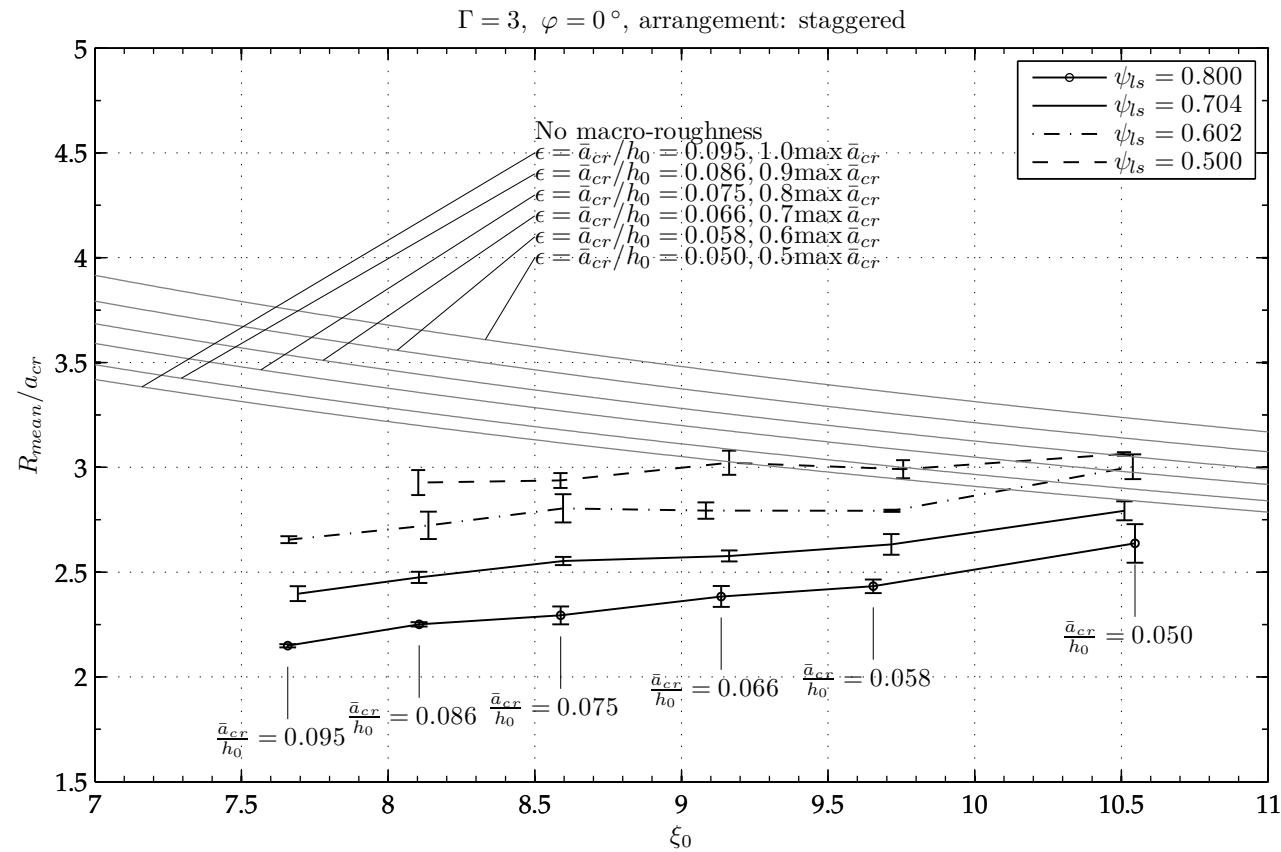

Fig. A2. The relative wave run-up $\left(R_{\text {mean }} / a_{\mathrm{cr}}\right)$ as a function of the surf similarity parameter $\left(\xi_{0}\right), \Gamma=3$. The experimental data are plotted according to the individual long-shore obstruction ratio. The error bars indicate the variation of the number of macro-roughness element rows. The grey parallel graphs indicate the relative run-up without the interaction with macro-roughness. The non-linearity of the applied waves is indicated as text which always refers to all error bars in the vertical above. 
MR elements on the shore. These are $b_{\mathrm{mr}}$ describing the edge length of an MR element, the distance between the MR elements $b_{\text {st }}$, the number of MR element rows $n, \phi$ defining the angle of rotation of MR elements with respect to the incident wave direction and $\Gamma$ indicates various sets of MR configurations. By means of the theorem of Buckingham it is hence possible to recast Eq. (B1) in the following form containing non-dimensional variables, which will be defined and discussed subsequent to Eq. (B2):

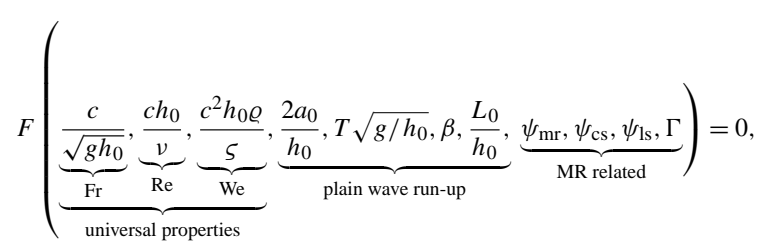

where $h_{0}$ indicates water depth over the horizontal bottom being utilized to define various non-dimensional variables. First, Froude, Reynolds and Weber numbers can be written. In hydraulic and coastal engineering, free surface problems are traditionally modelled under the assumption of Froude similitude. Such choice is admissible in case that viscous effects and surface tension are in a negligible order of magnitude. Based on linear wave theory involving the effects of kinematic viscosity, Schüttrumpf (2001) defines a critical Reynolds number to be $R e_{\text {crit }}=10^{4}$ below which the Froude number of waves propagating over horizontal bottom is no longer independent while values of $R e_{\text {crit }}=10^{3}$ are recommended during the run-up of waves with decreasing water depth and during overtopping. Besides wave propagation and run-up, the local MR Reynolds number should be above a threshold upon which viscous effects during wavestructure interaction is excluded. Those Reynolds numbers during propagation $R e_{\text {pro }}$ and during interaction $R e_{\text {int }}$ are defined as follows:

$$
\begin{aligned}
& R e_{\mathrm{pro}}=\frac{c h_{0}}{v} \\
& R e_{\mathrm{int}}=\frac{v b_{\mathrm{mr}}}{v} .
\end{aligned}
$$

Furthermore, in regard to minimizing viscous effects in scaled modelling of water waves Le Méhauté (1976) stipulates minimal flow depth not smaller than $0.02 \mathrm{~m}$ and wave periods not shorter than $0.35 \mathrm{~s}$. Due to limited water depth at the wave front it is anticipated that viscosity adds to overall scale effects in this spatially varying region of the flow.

The effect of surface tension to the propagation and runup of long waves in scale models was expressed in literature with the help of the extended dispersion relation (Le Méhauté, 1976), which analytically describes the dependency between Weber and Froude number. Dingemans (1997) expressed the effectiveness of the surface tension in an increase of gravitational acceleration but outlined that the influence of surface tension to wave action is mostly dominant when capillary waves are investigated. Due to the nature of surface tension, its effect on fluid motion amplifies where the fluid surface exhibits small radii of the liquid surface or when the distance to solid boundaries is rather small, i.e. for drops or bubbles (Peakall and Warburton, 1996). At most times during wave propagation and run-up, this requirement is not meet, so that scale effects due to surface tension can be excluded.

After discussing the choice of similitude and its implications for scale effects, a second group of dimensionless variables indicates parameters whose variation was often used to study wave run-up on a plain beach. It mainly depends on the relative wave height $\left(2 a / h_{0}\right)$ and the relative wavelength $\left(L_{0} / h_{0}\right)$. In addition, relative wave height and the slope angle $(\beta)$ listed in Eq. (B2) as two of the four dimensionless parameters determining the plain undisturbed wave run-up allow for the definition of the often used surf similarity parameter that is further discussed in Sect. 2.1 in connection with analytical run-up laws. It is defined as

$\xi=\frac{\tan \beta}{\sqrt{\frac{2 a_{0}}{L_{0}}}}$,

where index 0 refers to deep water wave parameters. In this research focussing on the influence of beachfront development on the maximum wave run-up, only the surf similarity parameter is varied through variation of the wave amplitude.

\section{B2 Laboratory effects}

In order to validate the scale model approach using Froude similitude it seems practical to check whether threshold limits of Reynolds and Weber number are met. Reynolds number during wave propagation over horizontal bottom yields $R e_{\text {pro }}=c h_{0} / v=\sqrt{9.81 \times 0.3} \times 0.3 / 10^{-6}=5.1 \times 10^{5}$. This Reynolds number is well above the threshold value defined by Schüttrumpf (2001). During long-wave interaction with beachfront development, it is recommended to refer the calculation of Reynolds number to the width of the MR elements $b_{\mathrm{mr}}$ which equals $0.1 \mathrm{~m}$. On the basis of PIV-based velocity measurements inside the MR area local velocities $v_{\text {loc }}$ in the range of 0.2 to $0.35 \mathrm{~m} \mathrm{~s}^{-1}$ are reported (Goseberg, 2011). With reference to Eq. (B4), it yields

$R e_{\mathrm{int}}=\frac{v_{\mathrm{loc}} b_{\mathrm{mr}}}{v}=2.0 \times 10^{5}-3.5 \times 10^{5}$.

Hence, viscous effects appear to be insignificant during the run-up phase of the long wave since inertial forces outweigh the viscous forces in the down-scaled model. It is also obvious that the Reynolds number is decreasing with decreasing horizontal velocity. This fact also suggests that viscosity develops into a significant parameter only when smaller flow velocities occur. The error stemming from these scale effects is present though negligible. What is more, with the aim to excluding surface tension effects biasing scale model results Novak and Cabelka (1981) state that down-scaled waves should always comprise a minimum wave length of $0.017 \mathrm{~m}$, 
minimum surface velocities of $0.23 \mathrm{~m}$ per s as well as a minimum water depth $h_{0}$ of $0.015 \mathrm{~m}$. These conditions are approximately met in this research though at some stages of the wave run-up or draw-down of the long wave, surface velocities or water depth could fall below these limits, while the wave length is always well above. Therefore, scale effects due to viscosity and surface tension appear to be considerably small during most of the tested conditions.

\section{Supplementary material related to this article is available online at \\ http://www.nat-hazards-earth-syst-sci.net/13/2991/2013/ nhess-13-2991-2013-supplement.zip.}

Acknowledgements. The authors acknowledge the partial support through the DFG/BMBF special Programme "Geotechnologies Early Warning Systems in Earth Management" (sponsorship code: 03G06666B). We acknowledge support by Deutsche Forschungsgemeinschaft and Open Access Publishing Fund of Leibniz Universität Hannover

Edited by: I. Didenkulova

Reviewed by: two anonymous referees

\section{References}

CEM US Army Corps: US Army Corps of Engineers Coastal Engineering Manual. U.S. Army Corps of Engineers, Washington, DC, Engineer Manual 1110-2-1100 (in 6 volumes), 2002.

Cox, D., Tomita, T., Lynett, P., and Holman, R.: Tsunami inundation with macro-roughness in the constructed environment, in: Coas. Eng. 2008, edited by: Smith, J. M., 2, 1421-1432, World Scientific, doi:10.1142/9789814277426_0118, 2009.

Dingemans, M. W.: Water wave propagation over uneven bottom, vol. Part 1 - Linear wave propagation of Advanced Series on Ocean Engineering - Vol. 13, World Scientific, Singapore, New Jersey, London, Hong Kong, 1997.

Fritz, H., Borrero, J., Synolakis, C., and Yoo, J.: 2004 Indian Ocean tsunami flow velocity measurements from survivor videos, Geophys. Res. Lett., 33, L24605, doi:10.1029/2006GL026784, 2006.

Fritz, H., Phillips, D., Okayasu, A., Shimozono, T., Liu, H., Mohammed, F., Skanavis, V., Synolakis, C., and Takahashi, T.: The 2011 Japan tsunami current velocity measurements from survivor videos at Kesennuma Bay using LiDAR, Geophys. Res. Lett., 39, L00G23, doi:10.1029/2011GL050686, 2012.

Goseberg, N.: The Run-up of Long Wave - Laboratory-scaled Geophysical Reproduction and Onshore Interaction with MacroRoughness Elements, Ph.D. thesis, Leibniz University Hannover, Hannover, Germany, 2011.

Goseberg, N.: A laboratory perspective of long wave generation, in: Proceedings of the International Offshore and Polar Engineering Conference, 54-60, 2012.

Goseberg, N.: Experimental run-up determination of single sinusoidal, solitary and $\mathrm{N}$-waves, in: Proceedings of the International Offshore and Polar Engineering Conference, 2013.
Goseberg, N. and Schlurmann, T.: Numerical and experimental study on tsunami run-up and inundation influenced by macro roughness elements, Coast. Eng. Proceedings, 1, doi:10.9753/icce.v32.currents.13, 2011.

Goseberg, N. and Schlurmann, T.: Interaction of idealized urban infrastructure and long waves during run-up and onland flow process in coastal regions, Coast. Eng. Proceed., 1, doi:10.9753/icce.v33.currents.18, 2012.

Goseberg, N., Wurpts, A., and Schlurmann, T.: Laboratory-scale generation of tsunami and long waves, Coast. Eng., 79, 57-74, 2013.

Goto, C. and Shuto, N.: Effects of large obstacles on tsunami inundations, in: Tsunamis: Their Science and Engineering, edited by: Iida, K. and Iwasaki, T., chap. Tsunami Run-up, 551-525, Terra Science Pub. Co., Tokyo/Reidel, Dordrecht, 1983.

Huang, N., Shen, Z., Long, S., Wu, M., Snin, H., Zheng, Q., Yen, N.-C., Tung, C., and Liu, H.: The empirical mode decomposition and the Hilbert spectrum for nonlinear and non-stationary time series analysis, Proc. Roy. Soc. A. Mat., 454, 903-995, 1998

Hunt, I. A.: Design of seawalls and breakwaters, J. Waterways Harbors Division, 85, 123-152, 1959.

Kawai, H., Satoh, M., Miyata, M., and Kobayashi, T.: 2010 chilean tsunami observed on Japanese coast by NOWPHAS GPS buoys, seabed wave gauges and coastal tide gauges, Int. J. Offshore Polar Eng., 22, 177-185, 2012.

Le Méhauté, B.: An Introduction to Hydrodynamics \& Water Waves, Springer-Verlag New York, Heidelberg, Berlin, 1976.

Madsen, P. A. and Fuhrman, D. R.: Run-up of tsunamis and long waves in terms of surf-similarity, Coast. Eng., 55, 209-223, doi:10.1016/j.coastaleng.2007.09.007, 2008.

Madsen, P. A. and Schäffer, H. A.: Analytical solutions for tsunami runup on a plane beach: single waves, $\mathrm{N}$ waves and transient waves, J. Fluid Mech., 645, 27-57, doi:10.1017/S0022112009992485, 2010.

Madsen, P. A., Fuhrman, D. R., and Schäffer, H. A.: On the solitary wave paradigm for tsunamis, J. Geophys. Res., 113, C12012, doi:10.1029/2008JC004932, 2008.

Moronkeji, A.: Physical modelling of tsunami induced sediment transport and scour, in: Proceedings of the 2007 Earthquake Engineering Symposium for Young researchers, Seattle, Washington, USA, 8-12 August 2007.

Müller, D. R.: Auflaufen und Überschwappen von Impulswellen an Talsperren, Mitteilungen des Instituts, Versuchsanstalt für Wasserbau, Hydrologie und Glaziologie der Eidgenössischen Hochschule Zürich, Zürich, d. Vischer, 1995.

Nicholls, R. and Small, C.: Improved estimates of coastal population and exposure to Hazards released, Eos, 83, 301-305, 2002.

Nistor, I., Palermo, D., al Faesly, T., and Cornett, A.: Modelling Of Tsunami-Induced Hydrodynamic Forces On Buildings, in: 33rd IAHR Congress: Water Engineering for a Sustainable Environment, 2009.

Novak, P. and Cabelka, J.: Models in Hydraulic Engineering - Physical principles and Design Applications, Pitman, Boston, 1981.

Oumeraci, H., Schüttrumpf, H., Möller, J., Zimmermann, C., Daemrich, K.-F., and Ohle, N.: Influence of Oblique Wave Attack on Wave Run-up and Wave Overtopping - 3D Model Tests at NRC/Canada with long and short crested Waves -, Tech. rep., Coastal Research Center (FZK), Hannover, Germany, fI Report No. 643 and LWI Report No. 859, 2001. 
Peakall, J. and Warburton, J.: Surface tension in small hydraulic river models - the significance of the Weber number, J. Hydrol., 53, 199-212, 1996.

Ramsden, J.: Forces on a vertical wall due to long waves, bores, and dry-bed surges, J. Waterw. Port. C-ASCE, 122, 134-141, 1996.

Ramsden, J. D. and Raichlen, F.: Forces on vertical wall caused by incident bores, J. Waterw. Port. C-ASCE, 116, 592-613, 1990.

Rueben, M., Holman, R., Cox, D., Shin, S., Killian, J., and Stanley, J.: Optical measurements of tsunami inundation through an urban waterfront modeled in a large-scale laboratory basin, Coast. Eng., 58, 229-238, 2011.

Schüttrumpf, H.: Wellenüberlaufströmung bei Seedeichen - Experimentelle und theoretische Untersuchungen, Ph.D. thesis, Technischen Universität Carolo-Wilhelmina, Braunschweig, 2001.

Shimozono, T., Sato, S., Okayasu, A., Tajima, Y., Fritz, H., Liu, H., and Takagawa, T.: Propagation and inundation characteristics of the 2011 Tohoku tsunami on the central Sanriku coast, Coast. Eng. J., 54, 1250004-1-1250004-17, doi:10.1142/S0578563412500040, 2012.

Small, C., Gornitz, V., and Cohen, J.: Coastal hazards and the global distribution of human population, Environ. Geosci., 7, 3$12,2000$.
Soares-Frazão, S. and Zech, Y.: Dam-break flow through an idealised city, J. Hydraul. Res., 46, 648-658, 2008.

Soares-Frazão, S., Lhomme, J., Guinot, V., and Zech, Y.: Twodimensional shallow-water model with porosity for urban flood modelling, J. Hydraul. Res., 46, 45-64, 2008.

Synolakis, C. E.: The runup of long waves, Dissertation, W. M. Keck Laboratory of Hydraulics and Water Resources, California Institute of Technology, 1987.

Tadepalli, S. and Synolakis, C. E.: The Run-Up of N-Waves on Sloping Beaches, Proc. Math. Phys. Sci., 445, 99-112, 1994.

Tomita, T., Honda, K., and Kakinuma, T.: Application of threedimensional tsunami simulator to estimation of tsunami behaviour around structures, in: Proceedings of the International Conference on Coastal engineering, edited by: Smith, J. M., 2, 1677-1688, World Scientific, 2007.

Yalin, M.: Theory of Hydraulic Models, The Macmillan Press Ltd., London and Basingstoke, 1971.

Yeh, H.: Maximum Fluid Forces in the Tsunami Runup Zone, J. Waterw. Port. C-ASCE, 132, 496-500, doi:10.1061/(ASCE)0733950X(2006)132:6(496), 2006. 